\title{
Escritura, memoria y narrativa en la literatura artúrica hispánica*
}

\author{
José Ramón TrujiLlo Martínez \\ joseramon.trujillo@uam.es \\ Universidad Autónoma de Madrid
}

\section{La escritura en la Edad Media}

La escritura constituye un sistema simbólico de representación, salvaguarda y transmisión de datos y hechos dignos de recuerdo mediante signos visibles convencionales. Su dominio ha sido, a lo largo de los siglos, un indicador de poder y de prestigio social. La aparición y preeminencia de la palabra escrita como técnica de gestión de la memoria se considera, por una parte, la línea que separa la barbarie de la civilización $^{1} \mathrm{y}$, por otra, una concesión sobrenatural con poderes mágicos ${ }^{2}$. La identificación de la civilización con la escritura es un constitutivo de todos los grupos humanos desde su aparición, derivada de su capacidad para la acumulación del conocimiento, y su valor instrumental y simbólico. Desde la Antigüedad tardía se observa en los textos la creciente desconfianza que provoca el empleo de la memoria oral, convertida en tópico (Quod non est in scriptis non est in mundo; verba volant...), y, en sentido inverso, los usos privilegiados a los que la escritura medieval se irá destinando: aseguramiento de la ley, gestión y agencia administrativa o económica, establecimiento de una memoria activa ${ }^{3}$. Muy pronto destacan los usos de la escritura en su empleo por las instituciones, pero

* Este trabajo se enmarca dentro del proyecto de I+D «La implantación de la Cortesía en la Edad Media a través de los testimonios literarios» (Ref. CM/JIN/2019-004) y de las actividades del Instituto Universitario de Investigación en Estudios Medievales y del Siglo de Oro (IEMSO) de la Universidad de Alcalá.

${ }^{1}$ Se encuentra asociada al desarrollo del gobierno, las artes y la economía, la agricultura y la ganadería, la industria y el comercio, pero también a la desaparición del conocimiento oral propio de culturas antiguas. «La escritura existe solamente en una civilización y una civilización no puede existir sin la escritura». Ignace J. Gelb, Historia de la escritura [1976], 3. a ed., Madrid, Alianza, 1985, p. 286.

${ }^{2}$ Alfred Bertholet, Die Macht der Schrift in Glauben und Aberglauben, Abhandlungen der Deutschen Akademie der Wissenschaften, Berlin, Philosophisch-historische Klasse, 1948. Franz Dornseiff, Das Alphabet in Mystik und Magie, 2. ${ }^{a}$ ed., Leipzig/Berlin, B. G Teubner, 1925. Alfred Charles Moorhouse, Historia del alfabeto [México D. F., Fondo de Cultura Económico, 1961], Madrid, Taurus, 1993, p. 245.

${ }^{3}$ Laurent Morelle, «Usages et gestion de l'écrit en Occident», en Usages et gestion de l'écrit documentaire (Occident, VI ${ }^{e}-X I I^{e}$ siècle): quelques considérations sur l'acte écrit, 
también los individuos comprenderán su utilidad en las prácticas sociales privadas cotidianas. Grandes comerciantes, mercaderes, artesanos, gremios urbanos serán los primeros, dentro de las nuevas clases emergentes, en comprender la ventaja de los documentos contractuales, de escrituración y procesales ${ }^{4}$. Pero esta identificación con la civilidad, pública y privada, es posible también -y de forma esencial- gracias al uso simbólico de la escritura, a su capacidad de perfilar una identidad colectiva compleja y de resguardarla del olvido a través de la memoria de los grandes hechos nacionales, como advertimos en estas palabras de 1222: «Porque los reales fechos a los fieles sean perdurables, mester es que sean socorridos por ayuda de escriptura de la olbidança de malvestad» ${ }^{5}$.

No obstante, el deterioro cultural y las deficiencias en la escolarización durante la alta Edad Media condujeron, con respecto a la Antigüedad tardía, a un retroceso de la cultura escrita en el Occidente europeo y a una baja alfabetización, que se calcula, según Cipolla, por debajo del $2 \%{ }^{6}$. En palabras de Gómez Rocha,

La Iglesia se constituyó, tras la caída de Roma, como la única estructura organizada común a toda la Europa cristiana, por lo que durante los siglos altomedievales el monopolio eclesiástico de la escritura será un rasgo permanente. Las producciones escritas se limitaron especialmente a los asuntos teológicos y piadosos, y las escuelas monásticas, parroquiales y catedralicias quedaron como las guardianas del arte de escribir, favoreciendo con ello una cierta sacralización de la escritura que llegó incluso a identificar la palabra de Dios con la palabra escrita. Este carácter sagrado de la escritura durante la Alta Edad Media puede considerarse la cumbre de la veneración al poder mágico y creador de la palabra7.

La reducción del número de personas que sabían leer y escribir y la identificación de los letrados con conocimientos por encima de los triviales con la clerecía -regular, secular o cortesana sin ordenar-, adjudicó un papel relevante a este grupo como garante y difusor del

Société des historiens de l'enseignement supérieur public, Paris, Publications de la Sorbonne, 2009, pp. 117-126.

${ }^{4}$ Especialmente, los contratos recogen la utilidad de la escritura como aseguramiento jurídico del contenido y sistema de pacificación de las partes ante posibles desacuerdos, pero los usos escriturarios permiten además la defensa contra el poderoso y las instituciones.

5 Julio González, Reinado y diplomas de Fernando III, Córdoba, Caja de Ahorros de Córdoba, 1983, vol. II, p. 204. El documento es de 22 de junio de 1222.

${ }^{6}$ Carlo M. Cipolla, Educación y desarrollo en Occidente, Barcelona, Ariel, 1970, p. 61; citado en Luis Casado de Otaola, «Escribir y leer en la Alta Edad Media», en Antonio Castillo Gómez (coord.), Historia de la cultura escrita. Del Próximo Oriente Antiguo a la Sociedad Informatizada, Gijón, Trea, 2002, p. 118.

${ }^{7}$ Javier Gómez Rocha, «Poder y escritura documental en la Edad Media. Los documentos del infante don Alfonso de Castilla del Archivo Municipal de Toledo», en Funciones y prácticas de la escritura: I Congreso de Investigadores Noveles en Ciencias Documentales, Madrid/ Escalona (Toledo), Departamento de Ciencias y Técnicas Historiográficas, UCM/Ayuntamiento de Escalona, 2013, pp. 109-114 (esp. pp. 109-110). 
conocimiento $^{8}$. El nivel de alfabetización aporta información significativa sobre la estructuración social ${ }^{9}$. El papel de los clérigos letrados, especializados en la escritura, se volverá muy notorio cuando la universidad y las cancillerías nobiliarias amplíen su actividad y el empleo de la escritura adopte de nuevo usos simbólicos. Resulta evidente en los propios textos el reflejo de las condiciones escriturarias a partir de mediados del siglo XIII en la península ibérica, presencia que irá variando hasta el reinado de los Reyes Católicos:

En Castilla, a partir de los siglos XII-XIII, presenciamos un importante aumento de la producción de documentos y una clara normalización de las cláusulas y tipologías documentales que servían más eficazmente a los deseos propagandísticos del rey, prestando mayor atención a su función simbólica, a la redacción y a la ornamentación. Todos estos cambios recaían en manos de auténticos profesionales de la escritura que por sus cualidades específicas fueron desplazando a los eclesiásticos que se encargaban de la documentación real ${ }^{10}$.

Importado desde el inglés (uses), en las últimas décadas se ha extendido entre los medievalistas el término «usos» de la escritura y los escritos para tratar de manera general las formas y técnicas de la escritura, las actividades relacionadas con la producción escrita, así como las condiciones sociohistóricas de sus prácticas y su recepción, incluyendo el estudio de la alfabetización (literacy) de una sociedad ${ }^{11}$. Siendo

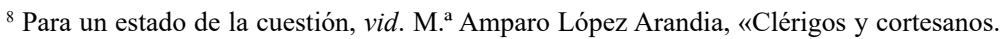
Balance y nuevas perspectivas metodológicas para el estudio de un grupo de poder en la Edad Moderna», en Ofelia Rey Castelao y Fernando Suárez Golán (coords.), Los vestidos de Clío. Métodos y tendencias recientes de la historiografia modernista española (1973-2013), Santiago de Compostela, Universidade de Santiago de Compostela, 2015, pp. 1029-1046.

La formación escolar de intelectuales se irá concentrando en las cancillerías cortesanas, escuela palatina, scriptoria monásticos, studia catedralicios y universitarios, que adquieren un papel central también en el desarrollo de los movimientos estéticos y las reformas espirituales y técnicas. Vid. Jacques Le Goff, La Civilisation de l'Occident médiéval, Paris, Arthaud, 1977. Pierre Riché, Éducation et culture dans l'Occident barbare: $s . V^{e}$-VIII ${ }^{e}$, Paris, Seuil, 1962. Jacques Verger, Culture, enseignement et société en Occident aux XII et XIII siècles, Rennes, Presses universitaires de Rennes, 1999.

${ }^{9}$ Giorgio Raimondo Cardona, «Per una teoría integratta della scritura», en Attilio Bartoli Langeli y Armando Petrucci (eds.), Alfabetismo e cultura scritta nella storia della società italiana, vol. II, Perugia, Università di Perugia, 1978, pp. 51-74. Giorgio Raimondo Cardona, «Sull' "etnografía della scrittura"», Scrittura e Civiltá, 1 (1977), pp. 211-218. Giorgio Raimondo Cardona, Antropología de la escritura, Barcelona, Gedisa, 1994. En este último libro, Cardona subraya al respecto que «la escritura es una de las formas menos igualitarias (cuyo uso está menos uniformemente distribuido en una sociedad) su circulación es la que más evidentemente mostrará los condicionamientos, contradicciones y los desniveles del modelo social» (p. 87) y que el escribiente «se asocia a menudo a un estado elevado» y tiene connotaciones positivas, aunque cuando se especializa en el caso de los escribas, el oficio no implica automáticamente el estatus (p. 89).

${ }^{10}$ Javier Gómez Rocha, «Poder y escritura documental...», art. cit.

${ }^{11}$ Rosamond McKitterick (ed.), The Uses of Literacy in Early Medieval Europe, Cambridge, Cambridge University Press, 1990. Karl Heidecker (ed.), Charters and the Use of the 
fundamental para el conocimiento de la cultura escrita, el objeto de este trabajo no es indagar en sus soportes, circulación y funciones históricas o en las relaciones entre poder y escritura a través de sus usos -bien estudiadas a estas alturas a través de la documentación jurídica y las crónicas de época-, sino ofrecer, dentro del marco descrito, una primera imagen del empleo de la escritura en la literatura artúrica hispánica como un artificio de construcción en niveles sucesivos de las acciones, de la memoria y del relato, desde la transmisión oral de los sucesos hasta la articulación narrativa. El corpus de textos seleccionado para ello, proveniente de traducciones de obras en prosa francesas de la primera mitad del siglo XIII atribuidas a Robert de Boron, alcanzó una amplia difusión a lo largo del siglo XIV en los medios cortesanos peninsulares, importando un modelo de construcción del sentido literario ${ }^{12}$. En primer lugar, se analiza la relación entre los sucesos y su fijación de la realidad a través del motivo del documento escrito, en segunda instancia se abordan brevemente las diferentes funciones de la lectura dentro de los textos y finalmente se estudia la voz narrativa y el juego de planos, centrándonos en el caso concreto de La Demanda del Santo Grial. La escritura se convierte en uno de los elementos básicos del propio conjunto textual, como desencadenante de la narración y también a la hora de servir de organización del discurso, como veremos en las siguientes páginas.

\section{LA FIJACIÓN DE LA REALIDAD: ESCRITURA Y AVENTURAS}

En la narrativa artúrica en prosa, la mención de la escritura en los textos se desenvuelve dentro de un campo semántico restringido (wortfeld), abierto y semiestructurado. Las principales voces responden a sustantivos concretos que aluden a un contenido (letras, carta, escrito, libro, cuento, historia) y sus soportes físicos (padrón, pilar, monumento,

Written Word in Medieval Society, Turnhout, Brepols, 2000.

${ }^{12}$ En adelante reservamos para las versiones castellanas los títulos Demanda (La Demanda del Sancto Grial: con los maravillosos fechos de Lançarote y de Galaz su hijo [Toledo, Juan de Villaquirán, 1515], ed. de José Ramón Trujillo, Alcalá de Henares, Editorial Universidad de Alcalá, 2017), Baladro (El baladro del sabio Merlín con sus profecías [Burgos, Juan de Burgos, 1498], ed. de M. ${ }^{a}$ Isabel Hernández, Oviedo, Trea, 1999), Lanzarote ([Madrid, BNE ms. 9611] ed. de Antonio Contreras y Harvey L. Sharrer, Alcalá de Henares, Centro de Estudios Cervantinos, 2006) y Tristán (Tristán de Leonís [Valladolid, Juan de Burgos, 1501], ed. de M. ${ }^{\mathrm{a}}$ Luzdivina Cuesta Torre, Alcalá de Henares, Centro de Estudios Cervantinos, 1999). Citamos mencionando los capítulos de los impresos entre corchetes para facilitar la localización de motivos extensos. Cuando no se indiquen otros títulos, nos referiremos a la Demanda. Empleamos los títulos Lancelot, Queste y Mort Artu para las versiones de la Vulgata francesa. Las citas concretas de textos franceses o portugueses se realizan a partir de las siguientes ediciones: Lancelot, ed. de Alexandre Micha, Paris/Genève, Droz, I y II, 1978; II y IV, 1978-1979, Queste del Saint Graal, ed. de Albert Pauphilet, Paris, Champion, 1923 y La mort le roi Arthur, ed. de Jean Frappier, Paris/Genève, Droz, 1936; A historia dos cavalleiros da mesa redonda e da demanda do santo Graal [Viena, Oesterreichische Nationalbibliotek, ms. 2594], ed. de Joseph Maria Piel e Irene Freire Nunes, Lisboa, Impremsa Nacional/Casa da Moeda, 1995. 
tumba, epitafio, silla/cátedra, tinta y papel, pergamino), a verbos relacionados (decir, contar, escrevir, tallar, mandar poner en, juntar, leer, jurar, traer, guardar) y adjetivos que atribuyen propiedades (verdadera, falsa, nuevas, entretalladas) en unidades fraseológicas más o menos estables a lo largo de las diferentes traducciones artúricas, y que es posible volver a encontrar con los mismos sentidos en el Amadís de Gaula. A ellas hay que añadir algunas voces asociadas referentes a quienes suelen realizar o transportar los escritos (clérigo, escriba, hombre bueno, mandadera, mensajero, etc.) o albergarlos (almario ${ }^{13}$, sillas).

En general, las alusiones a los personajes nobles y su relación con la escritura ${ }^{14}$ son realistas y el ambiente cortesano está reflejado con esmero; una atención a los discursos que destaca frente a la ausencia de descripciones de las joyas, la abundancia de las mesas y los ropajes, la calidad de las bebidas, y en general a los detalles del lujo cortesano. Los personajes aristocráticos saben leer, aunque la emergencia en el texto de diversas indicaciones e interrogantes nos permiten suponer con seguridad que se trata de una destreza valorada, aunque no necesariamente extendida, al menos entre la audiencia a quien va dirigido. Así se comprueba en el Tristán [3, f. 5r], cuando Merlín parte en busca del hijo del rey Meliadux:

Entonces hizo aparejar diez cavalleros e a Gorvalán, que le dio por ayo, e despediose del rey, e fuéronse su camino. E iban hablando de la gran traición que los cavalleros querían fazer, e que bien havían merescido la cruda e grave pena que se les havía dado. E cuando llegaron a la Fuente del León, Merlín llamó a Gorvalán e le preguntó si sabía leer. E Gorvalán le respondió que sí.

—Pues aquí en estas letras dize que aquí mató el rey Mares a Pernán, su hermano.

O en el Lanzarote [152, ff. 209r-v], cuando el caballero del Lago pregunta ante una tumba:

—Agora me decid -dixo Lançarote- ¿quién fue éste tan rico príncipe que yaze en tan rica sepultura?

- Señor-dixeron ellos- mucho fue alto ome e el más noble que nunca fue visto.

- ¡Ay, Dios! - dixo Lançarote- ¿quién fue?

- Señor -dixeron ellos- si sabedes leer, vien podedes saber quién es él que aquí yaze que a la cabezera de la su tumba lo fallaredes escrito.

${ }^{13}$ Del latín, «almarium», quizá en los textos artúricos a través del francés «almiere». Se documenta en textos castellanos como el Alexandre, c. 1240 («Sacó sus melesinas el meje del almario...», 888a) al menos desde el siglo XIII.

${ }^{14}$ Lo que en sociología de la escritura se denomina «evento», Giorgio Raimondo Cardona, Antropología de la escritura, op. cit., pp. 96-98. 
E Lançarote se fue a la cabeça de la tunba e falló las letras que decían: «Aquí yaze Galeote el fijo de la Fermosa Jayana que por amor de Lançarote murió».

Mientras «escrito» aparece raramente como sustantivo, el plurale tantum «letras», una de las voces fundamentales del campo, suele aparecer como en los ejemplos anteriores con la acepción antigua de mensaje breve consignado en papel o inscrito sobre piedra, y también servir como sinónimo de las tradicionales carta y misiva ${ }^{15}$, aunque el reparto en la frecuencia de este empleo varía significativamente entre textos: la voz «letras» aparece en 55 ocasiones en el Lanzarote ${ }^{16}, 54$ en la Demanda, 19 en el Baladro con ambos sentidos, mientras que en el Tristán aparece solo en 5 ocasiones y siempre con el primer sentido dentro del ámbito de la epigrafía. Las diferentes funciones de estos escritos de menor extensión permiten trazar una tipología, aunque sea de forma somera.

\subsection{Cartas y mensajes}

Una de las consecuencias derivadas de la movilidad de los caballeros y damas artúricos, así como de la sucesión de acontecimientos en general en lugares muy apartados de una vasta geografía, es la necesidad de cruzar mensajes y encontrarse al cabo de las novedades. Igual que los caballeros deambulan por yermos y florestas a la aventura, atraviesan fronteras y pasan de un lado al otro del canal de la Mancha o se recluyen en cortes, monasterios y yermos, numerosas doncellas y mensajeros transitan por las páginas trayendo y enviando información muy relevante para el desarrollo de la acción, la interacción entre los personajes y su caracterización psicológica.

Los textos cuidan con esmero la diferencia entre las notas escritas, denominadas siempre «letras» o «cartas», y las orales, denominadas de forma genérica «mensajes» o «nuevas», de breve extensión y contenido personal, que pueden intercambiarse con otras noticias o escritos:

Cuando don Lançarote ovo la carta leída, la donzella se fue para él y díxole:

—Señor cavallero, ¿quién sodes?

${ }_{15}$ «E los mandaderos fueron al rey Artur e diéronle las letras y el rey abriolas y bio que dezían ansí ...» Lanzarote [11, f. 7v.]. Este sentido se documenta entre los siglos XIV y Xv en autores como Gutiérrez Diez de Gamez, El Victorial, Madrid, Espasa-Calpe, 1940, p. 243, n. 17, o en Hernando del Pulgar, Crónica de los Reyes Católicos, ed. de Juan de Mata Carriazo, Madrid, Espasa-Calpe, 1943, t. I, p. 427.

${ }^{16}$ Debe tenerse en cuenta que la extensión del Lanzarote conservado es más de un $50 \%$ mayor que los productos impresos artúricos del siglo XVI. 
Y don Lançarote no se quiso encubrir y fue contra ella y umillósele. Y luego lo conoció ella y fue tan alegre que hera maravilla, y él la dixo:

-Amiga, ¿quién traxo aquí esta carta?

- Señor - dixo ella- yo la traxe.

-Agora -dixo él- id a mi señora la reina y dezilde que esta fabla que sobre mí fablaron los de la Tabla Redonda que en mal punto fablaron, que yo les faré aver ende vergüença. [Lanzarote 301, f. 334v]

Aunque apenas se mencione su materialidad y en alguna miniatura francesa entre las más antiguas se muestre la lectura de un mensaje sobre un rollo, probablemente de pergamino, la escritura de libros y textos largos parece diferenciarse netamente de las cartas. Así sucede en las pocas referencias que encontramos en los textos hispánicos. Los primeros se consignan en pergamino (también las miniaturas conservadas parecen optar por este o las tabletas como soporte): «E Merlín dixo: - Busca pargamino e tinta e yo te diré cosa que no cuidarás que ombre te lo pudiera dezir. E contarte he la muerte de Jesucristo, nuestro redemptor, e la fazienda de Josep e de Josefás todo como les avino...» [Baladro 5, f. 10v]. Las letras se consignan habitualmente en soporte papel ${ }^{17}$, y sin necesidad de dictar a un pendolista, como se aprecia con claridad en el Tristán: «Dixo ella: - Traime tinta e papel. E él trúxogelo luego. Ella escrivió una carta...» [5, f. 9r]; y en el Lanzarote: «E luego demandó al hermitaño tinta y papel y escrivió una carta y diola a la doncella» [296, f. 333r].

El pliego aparece cerrado sobre sí y en ocasiones autenticado mediante un sello, aunque no se mencionen sus figuras ni leyendas: «E los mandaderos fueron al rey Artur e diéronle las letras y el rey abriólas...» [Lanzarote 9, f. 7v]; «y sacó ende unas letras abiertas con su sello de oro e colgado con filos de oro» [Lanzarote 13, f. 8r]. Es deducible que la lectura de las letras en general se realiza en voz alta y de forma pública. Es común cuando se trata de mandatos («otro día de mañana imbió el rey sus letras por toda su tierra que decían que bien supiesen que aquél que de Lançarote supiese e lo non dixiese que faría d'él justicia...» [Lanzarote 145 , f. $145 \mathrm{r}-\mathrm{v}]$ ), pero también cuando se trata de noticias o de cartas con asuntos que afectan a la corte o a algún personaje principal. Así se advierte en el episodio de la falsa Ginebra, donde se debate la identidad de la reina: «y en tomando las letras cató a la reina con gran pesar y con gran bergüença e cuantos enderredor estavan, e después dixo a la doncella: - yo oí bien cuantas letras dezían» [Lanzarote 14, f. 11r]. Tras oír en la corte las razones de la mensajera de la Falsa Ginebra, Galván

${ }^{17}$ Los «relatos compuestos por Chrétien de Troyes sobre tabletas de cera entre 1160 y 1190, se convierten cuarenta o sesenta años después en una intrincada selva de aventuras del conjunto Lancelot-Queste-Mort Artu, cuyo original solo es imaginable escrito sobre papel». Martín de Riquer, «La novela en prosa y la difusión del papel», Anthropos: Boletín de información y documentación (ejemplar dedicado a: Martín de Riquer. Antología), 12 extra (1989), pp. 26-31. Cita en p. 30. 
contesta en defensa de la reina: «-Señor, nós oímos bien lo que las letras dezían y lo que la donzella dize...» [18, f. 13r]. Resulta bien interesante el conflicto entre la veracidad otorgada de antemano a lo escrito, especialmente si además viene sellado -la extensión del uso de matrices sigiladas desde el siglo XII es otro indicador material de una cultura cortesana bien asentada ${ }^{18}-$, y el posible falseamiento de la realidad, que llega a convertirse en relevante motivo narrativo.

La intensa movilidad de los caballeros y la corte artúricos acentúa la necesidad de conocer cómo les va a unos y otros, pues la corte funciona como un sistema jerárquico doble basado en el linaje y en el estado de opinión. Entrecruzados, validan la identidad social de los caballeros y su prestigio en contraste con un modelo ideal cortés. En los reencuentros en caminos y castillos, en las llegadas a la corte, en las peticiones de información a los mensajeros, las aventuras se detienen y se hace recuento oral de las acaecidas: se valoran los hechos de armas, se expresa el asombro ante las maravillas y la deslealtad de los antagonistas, se reconoce el valor y cortesía de los caballeros, la belleza de las damas y la bondad divina y mariana. La corte es una conversación incesante. La cortesía no existe sin interacción y sin validación social: el coloquio constante convierte los diálogos en un sistema de reconocimientos mutuos, de clasificación de acontecimientos y de la fama. En la sanción de los límites de las acciones corteses ${ }^{19}$. Para esta sociedad cortés en ebullición, el intercambio epistolar es igual de constante. En ocasiones las misivas escritas funcionan en paralelo a los mensajes orales ${ }^{20}$, como simples nuevas -noticias y especies sobre un personaje o situación- o con el fin de servir de petición o mandatos; en ocasiones destacadas, pierden el sentido de la urgencia y la inmediatez para desvelar elementos esenciales de una trama o el pasado de un linaje, como le sucede a Merengís el día en que accede a la Mesa Redonda y conoce su linaje mediante una carta que Claudín le aporta [Demanda, 187, f. 135r]:

Y despué[s], desarmáronlos; e sacó unas letras que traía en su seno, e diógelas a Merengís e díxole:

${ }^{18}$ Faustino Menéndez Pidal y de Montes, Elena Gómez Pérez, Matrices de sellos españoles (Siglos XII al XVI), Madrid, Ministerio de Cultura, Dirección General de Bellas Artes y Archivos, 1987.

${ }^{19}$ Sobre la doble gradación en méritos de armas y jerarquía de la gracia, véase José Ramón Trujillo Martínez, «Los contenidos y la estructura de la Demanda», en La demanda del Santo Grial, ed. cit., pp. XLI-XLVII.

${ }^{20} \mathrm{La}$ escritura presenta indicios de oralidad y las cartas y misivas se incardinan en la red de interacciones dialogadas y mensajes intermediados. Zumthor afirma de forma inequívoca que la novela medieval desde el siglo XII en adelante se encuentra «en la confluencia de la oralidad con la escritura» y que «el texto es muestra, tan pronto de una oralidad que funciona en una zona de escritura, como de una escritura que funciona como oralidad (y fue esto sin duda la pauta en los siglos XII y XIII)». Paul Zumthor, La letra y la voz. De la «literatura» medieval, Madrid, Cátedra, 1989, p. 117. 
—Estas vos embía una emparedada que yo hallé lexos de aquí no ha gran tienpo. E aquella dueña es tía de Perseval, e dixo que esta carta vos faría cierto de la cosa del mundo que más desseades saber, ca sabredes vuestro linaje quién es.

E cuando Merengís oyó estas nuevas, fue tan alegre que era maravilla. E tomó las letras, e dixo:

- Señor, vós me fezistes atán grande amor, que no vos podría yo galardonar; mas Dios me traya a tiempo que vos lo sirva.

Estonce tomó las letras e guardolas, ca no las quiso leer ante aquellos buenos hombres que aí eran. Y el rey le preguntó a Claudín dónde era. E Claudín lo dixo todo, e al rey plugo mucho aquello, ca mucho lo preciava de bondades de cavallería según lo avía dicho, e hízole mucha honra a él e al cavallero de las armas blancas. E preguntó a Cla[u]dín cómo se partiera del reino de Gaunes. Y él dixo toda la verdad, assí como el cuento lo ha contado.

La reserva de Merengís ante la lectura en voz alta indica el deseo de privacidad, observable en otras escenas cuando damas y caballeros se retiran de las grandes salas a las cámaras para departir o leer «privadamente», siempre acechados por las miradas de los demás cortesanos y sirvientes. Pero el mantenimiento del secreto en este caso indica también el deseo de los noveles de alcanzar la individualidad mediante los hechos de armas sin que el linaje intermedie. Los caballeros no leen solo textos, sino también los signos externos: blasones y señales, colores, riqueza de las armas o los ropajes. La errancia a la aventura y la ocultación de las armas -un «silencio heráldico»-, facilitarán los encuentros y combates. El anhelo de adquirir renombre e identidad se proclamará por la adquisición de unas armas propias.

El lector accede en ocasiones al contenido de una carta, resumido por uno de los personajes que lo ha leído; en otras, se incluyen completas o en parte las misivas. Así, en el episodio antes citado del Lanzarote [300, f. 334v], el caballero del Lago

cuando vido la carta sobre el padrón, tomola e leyola. E desque vio en ella lo que la reina le imbiaba a dezir y cómo le imbiava a salvar como al ome del mundo que ella más amaba e cómo alló aí que los de la Tabla Redonda hubieron fabla sobre él e dezía más la carta: «Yo vos ruego que seades contra los nuestros y que seades tan bueno y tan esforçado en el torneo que jamás los de la Tabla Redonda no osen dezir cosa contra vós». Y desque ovo leído la carta, plógole mucho de lo que ý falló escripto.

Pero el recurso sobresale en el Tristán, la obra que emplea por excelencia el recurso a las cartas -en general el intercambio epistolar y sentimental-, y que se inclina precisamente por especializar la voz «carta», que usa en 26 ocasiones, frente a su empleo en 24 en el Lanzarote, 10 en la Demanda y 3 en el Baladro. En varias ocasiones accedemos al 
contenido completo, que muestra las avanzadas dotes retóricas alcanzadas: Galeote escribe cartas al rey Artur, que se leen en la corte [25, f. $28 r$ ]. Iseo la Brunda envía una con Palomades como mensajero enderezada a Artur y Ginebra [30, f. 35r], pero explícitamente pensada para ser leída en alto: «A la corte del rey Artur: Yo, la reina Iseo, muger del rey Mares, me presento a vosotros. Vos fago saber que fue ventura que Palomades el Pagano me sacó de la corte del rey Mares por un don que le fue otorgado por mí, por servicio que me havía fecho ...». Lanzarote envía otra al rey Artur con un mensajero [68, f. 61r*]. De todas, resulta notable por su patetismo sentimental la que Iseo que a través de Brangel envía a Tristán [41, ff. 46v-47r], que se encuentra en Bretaña con Iseo de las Blancas Manos:

Tristán, hijo del rey Meliadux, yo, la sin ventura Iseo la Brunda, a ti salud, si el cabo de las cosas la acarrear puede. Tristán, alégrome e plázeme que todavía crescen los tus loores en proheza, tus muy grandes e gloriosos hechos; mas yo soy triste e mucho pesante por oír nuevamente el ensuziamento del tan limpio e entrañable amor, e el perdimiento del prez e honra de tu nombre de amador, ca dizen que tú, vencedor de todas las cosas, eres agora vencido de la tan sin fuerças Iseo de las Blancas Manos, fija del rey Oel de la Pequeña Bretaña, e que agora nuevamente eres casado con ella. ¿E cómo puede ser que Iseo la Brunda sea así olvidada e contada entre todas las gentes por barragana? E si por mi hermosura comigo as tenido amores, más fue a mí daño, que no provecho. E la mi hermosura e tu bondad de cavallería, enemigas fueron a mí muy crueles, que me pusieron en escuras cárceles, que a mí no pudieran ser contadas por virtudes, pues menos he de bien por ellas. [...]

Siguiendo las ideas avanzadas por Lida ${ }^{21}$, la crítica ha demostrado los préstamos e interferencia del Grimalte y Gradissa de Juan de Flores sobre el impreso de 1501. En palabras de Cuesta,

sin duda, las cartas fueron desde el primer momento los fragmentos preferidos por los refundidores y traductores de la novela para ejercitar sus dotes creativas. La tentación de refundir una carta, en la época de auge de la epistolar ficción sentimental, debía de ser demasiado fuerte para que el autor de la versión impresa se resistiese a ella, de forma que reescribió ambas cartas por completo ${ }^{22}$.

${ }^{21}$ M. ${ }^{\text {a }}$ Rosa Lida de Malkiel, «Arthurian Literature in Spain and Portugal», en Roger Sherman Loomis (ed.), Arthurian Literature in Middle Ages, Oxford, Oxford University Press, 1959, pp. 406-418.

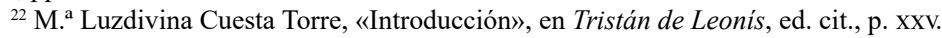




\subsection{Escritura y falsa verdad}

El poder de la escritura, su identificación con la realidad y su capacidad para desvelar la maravilla, incluso la voluntad divina, conduce a los hombres a actuar tomando siempre como verdad absoluta lo escrito. Como hemos indicado antes, la credulidad ante los textos es tal que sirve en varios hilos narrativos para acentuar la deslealtad y ruindad de los corazones arteros, capaces de conducir a la perdición a sus enemigos y súbditos, no ya mediante falso testimonio, sino incluso a través de falsificar -esta voz aparece en castellano ya en el siglo Xv en sustitución de falsear-cartas y apuntes epigráficos. Es el caso del episodio del Castillo Follón en la Demanda [273, f. 154v], donde los paganos que lo habitan consiguen encerrar a caballeros y doncellas que caen en la trampa:

Mas cuando supieron la verdad de la Tabla Redonda, e por cuamaño orgullo fuera levantada, e aquellos que d'ella eran cómo avían de andar por la tierra buscando las aventuras e las maravillas del mundo, e vieron que el rey Artur que era más poderoso que otro cristiano, pensó el señor del castillo cómo lo podría confonder a él e a su gente. E fizo fazer en un llano al pie del castillo un padrón, e sobre él un mármol muy fermoso. E fizo fazer en él letras que dezían: «O, tú, cavallero andante, que andas buscando aventuras, si osasses subir allá, suso al castillo e dieses cima a una aventura que allá ha, cosa no demandarás que no la ayas». E avía o[t]ras letras que dezían: «O, tú, donzella desaconsejada, que andas buscando cavallero aventuroso, si tú subieses allá, suso al castillo, no te partirás dende que no fuesses bien aconsejada a toda tu voluntad».

Capítulo CCLXXIV. Cómo los cavalleros e las donzellas estavan captivos.

E assí como vos digo dezían las letras del padrón, que fueron fechas por engañar los cavalleros e las donzellas que por allí passassen. E bien eran engañados, que tanto que por aí passassen e subían al castillo, metíanlos todos en prisión, y estavan aí fasta que morían; y las donzellas teníanlas por barraganas, e desque eran enfadados d'ellas, fazíanlas aprender a labrar seda, e assí las tenían por siervas para siempre. E por tal razón como vos digo, fizo fazer las letras en el padrón el señor del castillo, donde avino que muchos buenos hombres murieron por ende, e más de quinientas donzellas fueron aí captivas.

O aún más escandalosa, la traición de Mordrec [422, f. 187r]: cuando los romanos son vencidos, Mordrec se alza contra el rey y consigue que los hombres del reino crean la noticia de la muerte de Artur y se alineen de su lado:

E cuando Morderec vio que la tierra era toda en su poder, luego pensó cómo fiziese traición e qué guisaría que su tío que no oviese a qué tornar. 
Y él amava a la reina tanto que nunca Lançarote la amó tanto. E fizo estonce fazer unas letras falsas e fízolas aduzir como de camino e fízolas leer ante los ricoshombres que aí estavan asentados. E las letras dezían que el rey moriera en Gaunes e que mandara a los ricoshombres de Londres que fiziesen rey ha Morderec e que le diesen a la reina Ginebra por muger. E los de Londres, que bien pensaron que era verdad así como las letras dezían, fizieron rey a Morderec.

Si el ardid y la simulación resulta en ocasiones disculpable como parte del ingenio de los caballeros y las damas -recuérdense las simulaciones y añagazas de los amantes en el Tristán e Iseo ${ }^{23}-$, y resulta esperable de los paganos, la traición del caballero en el combate y en las razones resulta reprobable y descortés, siendo en el caso de la escritura la falsedad equivalente al delito de traición, y merecedora del castigo y el desprecio como bellacada.

\subsection{Hitos, narración y epigrafía}

La errancia a la aventura conduce a los caballeros a atravesar geografías, aventurarse en los mares y recorrer los caminos que atraviesan páramos y florestas en busca del reconocimiento o de una señal de la Providencia. Los caminos se entrecruzan acercando o juntando a los personajes, en ocasiones alejándolos hasta el extravío. La exposición a lo desconocido, la intervención de las fuerzas sobrenaturales y de las pasiones, las bifurcaciones de senderos, la soledad o el retiro selváticos, conducen al desvío en el camino. En ocasiones la desorientación moral ocasiona la pérdida del hilván de las historias individuales ${ }^{24}$. Hitos geográficos y narrativos al tiempo, algunos puntos concretos -hoy hablaríamos con menor propiedad de plot-points- constituyen el gozne sobre el que bascula una línea de desarrollo personal o del propio relato. De forma muy significada, el caballero asiste en momentos de indecisión a la lectura de mensajes anónimos -«falló letras que dezían» es la unidad fraseológica más empleada- que lo orientan, en uno u otro sentido, a la hora de abordar la siguiente acción, o lo retan a (no) realizar una acción. Sobre lápidas encontramos indicaciones talladas en caminos y bifurcaciones, que suponen más que la información sobre un peligro o lugar, más bien un acicate para que el caballero muestre su valía. Un

${ }^{23}$ José Ramón Trujillo Martínez, «Tristán y el amor salvaje», en David Arranz (ed.), Amores canallas, Madrid, Pigmalión, 2019, pp. 303-317.

${ }^{24}$ Cfr. el desarrollo de esta idea de geografías simbólicas e itinerancia en la forja de la identidad caballeresca en José Ramón Trujillo Martínez, «El caballero en la floresta. Aventura y construcción de la identidad del héroe épico», en Roberto Cáceres (ed.), Héroes, dragones y magia. De la epopeya homérica a World of Warcraft, Madrid, Aluvión, 2018, pp. 29-61. 
tipo especial los constituyen los mensajes inscritos en un «padrón» ${ }^{25}$, monumento que sirve de hito en los caminos y entradas de castillos y cementerios. Así, por ejemplo,

Y Éstor se fue su camino que no curó d'él, e andubo tanto que llegó a dos pedaços de padrones que estavan en medio del camino, y avía letras que decían ansí: «Ya no irá ninguno de aquí adelante, si no quisiere su daño». Y Éstor leyó las letras, mas por eso no se tornó un paso, antes se fue adelante, ca dixo que no devía haver ninguno miedo [Lanzarote 208, f. 283]

Este tipo de letras, consignadas de forma epigráfica sobre lápidas, madera o la superficie del propio monumento, no son solo memoria construida, sino información valiosa que aporta indicaciones sobre la próxima aventura. Un ejemplo señero lo encontramos en los cruces de caminos, donde el caballero debe tomar el adecuado a su destino. En la búsqueda, Galaz y su escudero Melián de Dinamarca

E anduvieron aquel día, e otro, sin aventura fallar, ansí que un día de lunes les avino que llegaron a una cruz grande que partía dos carreras, y estava aquella cruz a la entrada de un gran llano, e la cruz era de madera, mas no era muy vieja. E, e fallaron aí letras entretalladas que dezían:

«Tú, cavallero andante, que vas las aventuras buscar e demandar, aquí ha dos carreras: una a diestra e otra a siniestro. Aquella de siniestro te defiendo yo, ca sobejo deve ser bueno el que en ella entrare, ca no podrá ende salir sin muy gran daño de aquella. De diestro no te digo tanto peligro, mas si aí entrares e no fueres muy bueno, no podrás acabar aí cosa».

Cuando Melián vio las letras, dixo a Galaz:

- Señor, por Dios e por cortesía, dexadme esta carrera de siniestro, ca por aquí podré yo provar si avrá en mí loor de cavallería. [Demanda $52-53$, f. 107 r]

${ }^{25}$ Del bajo latín «petronus», a través de francés «perron» o quizá del provenzal «peiro». La voz en francés aparece ya en la Chanson de Roland («Sur un perrun de marbre...»). Se trata de una estructura o monumento en piedra o mármol compuesta habitualmente de una columna, coronada o no con una cruz o un globus cruciger, sobre una escalinata, símbolo de jurisdicción y poder. Habituales en las ciudades del norte de Francia y el principado de Lieja, servían para impartir justicia e imponer castigos. Aunque no lo recogen con este sentido los glosarios antiguos (Vocabulario español-latino de Nebrija [Salamanca, 1495?], Vocabulario de las dos lenguas toscana y castellana de Cristóbal de las Casas [Sevilla, 1570], etc.) el Diccionario de autoridades (1737) da una definición muy ajustada en una de sus acepciones: «Se llama asimismo la colúna de piedra, con una lápida o inscripción de alguna cosa que conviene sea perpétua y pública». Con el sentido de columna, pero sin inscripciones, lo encontramos en Lanzarote [144, f. 123r]: «havía de la una parte y de la otra muy gruesos padrones de mármol que más había de mucho. Encima d'ellos estaban calçadas muy fuertemente firmadas e en las calçadas estaban muchas varras de fierro...». En otros casos, puede ser un mensaje en piedra, como cuando Lanzarote y su escudero se encuentras «con una donzella que venía a pie y traía un padrón en los braços y don Lançarote la salvó y ella no a él...» [Lanzarote 266, f. 316r]. 
Melián, recién ordenado caballero, rechaza con soberbia el camino diestro a pesar de las advertencias y el castigo será consecuencia de sus acciones desviadas ante las tentaciones que halla en él: la corona de oro y una doncella que sustrae a otros.

También encontramos mensajes inscritos que advierten a personajes señalados que pueden o no entrar en recintos, realizar gestas o, en caso extremo, acceder a la contemplación del Grial:

E luego se partieron los tres compañeros de los nueve, e Galaz e sus compañeros anduvieron tanto que al tercero día llegaron al mar e fallaron la nave do Galaz salvó la espada de la Estraña Cinta; y fallaron letras que dezían ninguno no entrasse aí si no fuesse de buena creencia. E santiguáronse y entraron dentro, e fallaron aí un lecho muy noble en que estava muerta la hermana de Perseval. [379, f. 178v]

En ocasiones, la escritura sirve como recurso caracterizador de un personaje. Las letras no solo hacen manifiesta la cobardía de Galván, sino su premeditado cálculo ante el peligro. La acción que desencadenará la muerte de Iván de Cinel, con la posterior cadena de acciones de venganza, con su hermana reclamando a los caballeros que acometan al traidor de Galván y una sucesión de justas y derramamiento de sangre insospechados:

E otro día llegaron a un castillo muy fuerte e muy hermoso que estava en una ribera, mas parescioles que algo era yermo. E cuanto llegaron a la puerta, fallaron en un padrón letras de oro en piedra que dezían: «Aquí yaze Lamorante, el que mató Galván, sobrino del rey Artur». E después a ver lo que las letras dezían, e por esto defendían los del castillo que ninguno del linaje del rey Artur que no fuesse osado de entrar en aquel castillo, ca, si entrasse, todo el aver del mundo no le sa[1]varía de muerte. E desque ellos ovieron leído las letras, ca Galván sabía muy bien leer, $\mathrm{e}$ sabía muy bien cómo era todo, tornó atrás rodeando el cavallo. E dixo:

- Iván, tornemos, ca si allá entramos, muertos somos.

E Iván, que no dudava muerte si le aviniesse morir, dixo:

- Por Dios, señor, tal no averná, si Dios quisiere, que por miedo de muerte me buelva, ca nos lo ternían a mal, e por cobardía.

E Galván dixo:

- Tengan si quisieren, ca yo tornarme quiero, que llanamente veo mi muerte si adelante vó. [Demanda 106, f. 118v; la cursiva es nuestra]

En ocasiones la inscripción se encuentra en un cementerio, como en el episodio en que Lanzarote

Falló una floresta. Y a la entrada d'ella estaba una hermita en que estava un hermitaño, y ante la hermita estava en el cimenterio una cruz en un padrón de marmól. Y cuando don Lançarote vido la cruz, cató sobre el padrón y vio letras vermejas que dezían: «Oyes, tú, cavallero andante, 
que buscas las aventuras si tú no quieres tu muerte o tu desonra, guarda que no entres en esta floresta, ca te non podrás ende partir sin una d'estas dos cosas». [Lanzarote 265, f. 315r]

Pero de todas las funciones de la escritura en la prosa artúrica, una de las más notables es la relacionada con las sepulturas y sus epitafios, que se encuentran muy presentes en todas las obras ${ }^{26}$. La mención de las tumbas, como ejemplo de un tipo de muerte para el resto de los caballeros, forma parte de la tradición artúrica y convierte cada una en un jalón, en materia progresiva de una memoria fragmentaria a través de los epitafios como sucede con Bandemagus cuando entra en la cueva y descubre dónde yace Merlín («el monumento fue contra los pies d'él e vio en la campana e en el sepulcro letras»). Los epitafios incluyen el nombre y el motivo de las muertes para perduración de su memoria y ejemplo, pero también como advertencia. Como señala Colliot, alguno tiene carácter profético al conducir al caballero que lo lee a iniciar una aventura. En las ramas finales del ciclo abundarán las bajas producidas en la búsqueda, a las que se suman a las del tumultuoso fin del reino ${ }^{27}$. El final de lo más granado de la Mesa Redonda conduce a una inusitada acumulación de sepulcros, hasta el punto de convertir Sant Estiano de Camaloc en una necrópolis literaria: en los textos franceses asistimos a los entierros de los sobrinos de Artur, Agravain, Gerrehet, Gaheriet y Gauvain, así como de Gaheris de Kaherren o la dama de Escalot.

La costumbre en el reino consiste en confeccionar un sepulcro, que puede llegar a ser muy ricamente ornado. Así, por ejemplo, Lanzarote contempla

dentro en los arcos una muy rica tumba cual nunca tal viera él ni ome del mundo, que hera toda de oro fino e de piedras preciosas, que estava toda labrada de diversas maneras e de muy muchas cosas de figuras e de otras cosas, que tal tumba de tal manera nunca viera ni ome del mundo que la

\footnotetext{
${ }^{26}$ Vid. al respecto Régine Colliot, «Les Épitaphes arthuriennes», Bulletin bibliographique de la société arthurienne, 25 (1973), pp. 155-157; Helen J. Swift, Representing the Dead: Epitaph Fictions in Late-medieval France, Cambridge, Boydell \& Brewer, 2016; Antonio Contreras, «Tumuli Britanniae: consideraciones sobre las tumbas en la literatura artúrica castellana», Butlleti de la Reial Acadèmia de Bones Lletres de Barcelona, 52 (2009-2010), pp. 119-135; e Id., «Las tumbas en la Demanda del Santo Grial castellana», en Jesús Cañas Murillo, Francisco Javier Grande y José Roso (eds.), Medievalismo en Extremadura. Estudios sobre Literatura y Cultura Hispánicas de la Edad Media, Cáceres, Universidad de Extremadura, 2009, CD, pp. 1027-1036.

${ }^{27}$ Como bien subraya Laranjinha, mientras el autor de la Vulgata se preocupa por preservar la memoria mediante los sepulcros, debido a su espíritu apocalíptico el Pseudo Boron incide en la destrucción de todos los restos del mundo artúrico, castillos, torres, tumbas (de Lancelot y Galehot), incluso el rey Marc profana la de Lancelot para quemar su cuerpo. Ana Sofia Laranjinha, «L'apocalypse arthurienne dans le cycle du Pseudo-Boron, ou comment survivre après la fin des temps», e-Spania, 17 (feb. 2014). En línea. DOI: https://doi. org/10.4000/e-spania.23201.
} 
non oviese visto no podría asmar la fermosura que en ella avía de tales cosas como en ella estavan. [...]

- ¡Ay, Dios! -dixo Lançarote- ¿quién fue?

- Señor -dixeron ellos- si sabedes leer, vien podedes 209v saber quién es él que aquí yaze que a la cabezera de la su tumba lo fallaredes escrito. E Lançarote se fue a la cabeça de la tunba e falló las letras que decían: «Aquí yaze Galeote el fijo de la Fermosa Jayana que por amor de Lançarote murió». [Lanzarote 152, f. 208v]

Agravain y Gueherret no merecen la memoria de su muerte, en tanto que Gauvain desea dejar constancia de su empecinamiento contra Lancelot y su arrepentimiento ante tal acción. En el caso de Galván, como en el caso de las explicaciones (senéfiances) de las maravillas, los textos franceses se duplican, entre la petición del caballero, que expresamente desea dejar memoria de sí y de sus andanzas, y la realización posterior de su deseo. Así sucede con Gauvain, en su lecho de muerte dice al rey:

Sire, je vos requier que vos me façois enterrer a Kamaalot ovec mes freres, et voil estre mis en cele tombe meïsme ou li cors Gaheriez fu mis, car ce fu li hons dou monde que je plus amai. Et fetes escrire sus la lame: «Ci gist Gaheriez et Gauvains que Lancelos ocist par l'outrage [desmesura] Gauvain». Cest escrit voil je que i soit mis, si que je soie blasmez de ma mort, si com je l'ai deservi. [Mort Artu 196, p. 396]

Gauvain muere arrepentido y exigiendo constancia de su desmesura contra el mejor caballero del mundo ante todos y ante la posteridad. Unas páginas más allá, en el \#200 encontramos que los caballeros conducen el cadáver de Gauvain a Kamaalot donde a hora de tercia, tras reunirse una multitud en la iglesia, es enterrado:

Il l'ensevelirent en la tonbe meïsmes ou Gheriez ses freres gisoit, et escristren sus la tombe letres qui disoient: «Ci gist Gaheriez et Gauvains que Lancelos ocist par l'outrage Gauvain». Einsi fu messires Gauvaiins enterrez par compaignie avec son frere en l'eglise de Camaalot qui estoit de monseigneur saint Estienne. [Mort Artu 200, p. 402]

En el caso de las tumbas de Baudemagus (en la Queste) y de Gaheris, los epitafios informan a Lacelot y Mador de la Porte de estas muertes y sus causas, desencadenando nuevas acciones, especialmente la venganza como señalara Colliot ${ }^{28}$. Los textos hispánicos incluyen varias mues-

${ }^{28}$ Algunas inscripciones insisten en denunciar el comportamiento descortés y asesino de los caballeros, en el antiguo sentido que tenía padrón: «Metaphóricamente se llama la nota pública de infamia o desdoro, que queda en la memoria, por alguna acción mal hecha. Lat. Nota infamia. Sandov. Hist. Ethiop. Lib. 1, cap. 3, Ponían sobre su sepultura una cruz, como por señal y padrón, por no llamarle sambenito de su infidelidad y oprobio» (Autoridades 1737). Por ejemplo, antes de suicidarse, Esclavor encarga un sepulcro de plata para su hijo, «E las letras fueron hechas sobre el monimento de Palomades, e dezían cómo le matara Galván con 
tras con funciones similares a las inscripciones francesas, que se separan en mayor o menor medida de su fuente de inspiración. Así describe la sepultura de los sobrinos de Artur en Camaloc:

Y el rey se acordó a este consejo e levaron a Galván los hombres buenos assí amortescido como estava, e yugó aí todo el día e toda la noche que nunca habló. E toda aquella noche fue el duelo en el palacio muy gran e por la villa. E otro día de mañana, desarmáronlos e fízolos el rey soterrar mucho honradamente cada uno según lo merescía, e a Güereches y a Agravaín fízoles fazer tan ricos monimentos e tan fermosos como a fijos de rey conviene. E hízolos ambos poner en par, y esto fue en un monesterio de Sant Estavan de Camaloc, e contra las cabeças d'estos dos fizo poner otro monimento mucho más rico e más fermoso que ninguno d'estos e fizo meter ý a Gariete. E por Gariete veríades estonce fazer duelo a todas partes de obispos, e de arçobispos, e de muchos buenos prelados de la tierra que vinieran aí e de muchos altos hombres que aí eran e tantos aína que no podían llegar a la sepoltura. E hizieron a los muertos tanta honra cuanto ellos pudieron, mas mayor a Gariete, que era mejor que los otros, e fizieron mayor e más honrado el su monimento que'l de los otros. E hizieron ý letras que dezían: «Aquí yaze Gariete, sobrino del rey Artur, que Lançarote del Lago mató». E otrosí fizieron escrevir sobre los otros sus nombres, e quién los matara. [Demanda 408, f. $184 \mathrm{v}]$

La lectura de los epitafios significa, más que la nómina memorable de los héroes, la síntesis de un reino extinguido y de sus pecados: la soberbia de Gauvain, la artería del rey Marc el envenenador, la desgracia de Lucán, aplastado por su rey, los trágicos destinos de Palomades y su padre, víctimas de Galván, la memoria de la traición de Mordrec... Acabados los años de esplendor y maravillas, conservadas exclusivamente en el relato guardado cuidadosamente por los clérigos de Camaloc, la imagen fragmentaria que los epitafios dejan a la posteridad a través de los sepulcros sobre los que se encuentran es la de una caballería terrena que ha incurrido en todos los pecados imaginables y que ha perecido por ellos. Solo tres caballeros destacan y dejan tras de sí una pálida memoria del valor de la caballería tras el crepúsculo sangriento del mundo caballería terrenal: Artur, conquistador de doce reinos, Lancelot «li mieldres chevaliers qui onques entrast ou roiaume de Logres fors solement Galaad son fils», y sobre todo las valiosas aventuras del caballero santo.

su hermano Agravaín con gran maldad, siendo su compañero y estando llagado; e cómo su padre Sclavor se matara por sí e cómo las letras eran de su sangre» [Demanda 361, f. 173v]. O también tras el asesinato de Bren el Negro al que Galaz «hízolo soterrar lo más honradamente que pudo, e fizo hazer sobre la tumba unas letras que dezían cómo le matara el rey Mares a traición» [Demanda 259, f. 151r]. 
Algunas de las inscripciones sobre un padrón son singulares por su naturaleza preternatural. De entre todos, resulta conocidísimo el pasaje legendario de la espada en la piedra:

E después que ofrecieron, salieron fuera ante la iglesia, que avía una plaça grande e llana, en la cual vieron un padrón cuadrado; mas nunca pudieron saber de qué piedra era, pero algunos dixeron que era de mármol. E sobre aquel padrón avía una yunque en que estaba metida una espada fasta el arriaz. E cuando la vieron, maravilláronse e fuéronlo dezir al arçobispo. E el arçobispo, cuando lo oyó, tomó del agua bendicta e las reliquias de la iglesia e, con todos los clérigos e con todo el pueblo, salió fuera. E cuando vieron el padrón e la espada, rezaron salmos e oraciones e echaron agua bendita; e cató el arçobispo el espada e fallole letras de oro que dezían: «Quien fuere tal que esta espada pudiere sacar será rey d'esta tierra por elección de Jesucristo». E después que leyó las letras díxolo al pueblo. E el padrón fue dado a guardar a diez ombres buenos; e los cinco d'ellos eran clérigos e gradecieron mucho a Nuestro Señor lo que les mostrava. [Baladro 17, f. 37v]

La inscripción es a la vez mandato y profecía, por lo que se trata de un tipo de escritura que toca con lo maravilloso proyectando hacia el futuro las acciones predestinadas. Finalmente, Artur joven se alza con el galardón cuando el hijo mayor de Antor le pide que traiga una espada:

E el mancebo, que era muy bueno e buen servidor, dio de las espuelas al cavallo e fue a la posada por la espada; e no falló espada ninguna, ca su madre la tenía guardada en $\mathrm{s}[\mathrm{u}]$ cámara, que fuera a ver lo del padrón. E cuando vio el mancebo que no podía aver el espada ni otra, fuese para el padrón e vido la espada, que aún nunca la provara, e pensó, si pudiese, que la llevaría a su hermano. E así, de cavallo como andava, llegó al padrón e tomola por el arriaz e sacola e metiola so la falda de su albornoz e llevola a su hermano, que lo atendía fuera de la villa. E el hermano, desque lo vio, preguntole si traía el espada. E él dixo:

- Por Dios, no la pude fallar, mas tráigovos la espada del padrón. [Baladro, ibid.]

Otro pasaje de prueba y predestinación anunciada de importancia similar lo encontramos en el episodio del padrón de Merlín ${ }^{29}$. El auditorio asiste a la extraordinaria venida del padrón a través del agua y al fracaso de todos en la prueba, salvo el elegido:

- Señor, aquí so este vuestro palacio aportó agora un padrón de mármol asaz grande, a do está metida una espada, e a par d'ella está una vaina colgada e letras estrañas. E yo vos digo que vi el padrón assí

${ }^{29}$ Al pie del padrón de Merlín se citan en duelo Tristán y Palomades [Tristán 67, ff. $\left.72 \mathrm{r}-61 \mathrm{r}^{*}\right]$. 
venir andando sobre el agua como si fuesse un madero. [...] E cuando el rey llegó a la ribera, e vio el padrón e la espada aí metida por el encantamiento de Merlín, assí como el cuento lo ha devisado, e vio la vaina que estava cerca de la spada e las letras que Merlín escriviera, fue todo espantado, e dixo:

-Nuevas vos diré agora: sabed que por esta espada será començado el mejor cavallero del mundo, y esta es la prueva por que se ha de conocer, ca ninguno, si no fuere el mejor cavallero del mundo, no podría sacar sta spada d'este padrón. [Demanda 8 , f. 98v]

\section{LAS HUELLAS SAGRADAS}

\subsection{Las maravillas del reino}

\section{La prueba del padrón de Merlín en el exterior finaliza y}

Después d'esto, tornáronse al palacio e mandaron por mesas, e los clérigos que se trabajavan de catar a las sillas de la Tabla Redonda, e que lo avían de fazer, començaron de catar de una parte e de otra e fallaron estonce que en dos sillas no avían ningunas letras, sino nuevas, assí como si fuessen fechas estonce. E la una silla era escripto el nombre de Erec, y en la otra el nombre de Helaín el Bran $<\mathrm{t}>$ [c]o [Demanda 8, f. 99r]

Del pasaje con la inscripción mágica, pasamos a un escenario relacionado, pero diferente en su esencia espiritual: el de las señales de la Providencia ${ }^{30}$, en este caso sobre la Mesa Redonda que, como otros elementos simbólicos como el Grial, son en realidad reliquias sagradas. Más allá del papel intrínseco que hemos analizado como vehículo de información e intercambio, o como sistema de orientación, se emplea la escritura como mecanismo para otorgar verosimilitud a algunas de las maravillas o los milagros del reino de Gran Bretaña, o para explicar su sentido a los caballeros y a lectores. En general, la escritura es una competencia indistinta de caballeros y doncellas, pero el uso de la escritura memorialística queda en manos de varones, y la maravillosa y sagrada, salvo en casos como el de Merlín, llega a borrar las manos que realizan $^{31}$. Uno de los milagros destacados es el episodio del Asiento Peligroso (Siege Perilous) de la Tabla Redonda, profetizado en el ciclo

${ }^{30}$ Para las tipologías y caracterización de maravillas, encantamientos y milagros, vid. José Ramón Trujillo Martínez, «Magia y maravillas en la materia artúrica hispánica. Sueños, milagros y bestias en la Demanda del Santo Grial», en José Manuel Lucía Megías y M. ${ }^{\text {a }}$ Carmen Marín Pina (eds.), Amadís de Gaula: quinientos años después. Estudios en homenaje a Juan Manuel Cacho Blecua, Alcalá de Henares, Centro de Estudios Cervantinos, 2008, pp. 789-818.

${ }_{31}$ «Cuando la escritura es una de las manifestaciones vinculadas con la escritura sagrada y religiosa, será actividad reservada a los varones, porque aun cuando las mujeres puedan desempeñar un papel religioso (sacerdotisas, corifeas, monjas) nunca son admitidas a participar en el conocimiento sagrado», Giorgio Raimondo Cardona, Antropología de la escritura, op. cit., p. 93. 
en prosa junto con la Torre Venturosa como una de las maravillas a las que dará cumplimiento «don Galás, el muy noble cavallero, aquél que se asentó en la Silla Peligrosa de la Sancta Tabla de Josep Abarimatía, en la cual no se asentó caballero que muerto o tullido no fuese» [Lanzarote 95, f. 51r]. En los textos franceses, Brumante el Orgulloso, sobrino del rey Claudás de la Tierra Desierta, a pesar de la profecía decide ocupar el sitio reservado al caballero elegido. Al sentarse, su castigo es quedar reducido a cenizas por un fuego maravilloso. En el momento de arder, entrega a Lancelot una carta donde aclara su linaje y desvela sus motivaciones: demostrar su valor y alcanzar una maravilla que el primer caballero no se atreve a acometer [Lancelot-Graal, BNF fr. 120, 474r]. Presente en A demanda do Santo Graal, el artificioso mecanismo de retrospección (la lectura del escrito salvado en última instancia de las llamas) permite conectar en la mente del lector la cadena orgullo-castigo divino, adelantada por el sobrenombre del caballero, y a resaltar la predestinación de Galaz ${ }^{32}$. Este finalmente ocupa el asiento y los caballeros recuperan la voz, pues habían quedado demudados con su entrada maravillosa [Demanda 14-15, ff. 99v-100r].

Pero quizá el episodio más significativo - por su posición en la narrativa, su desarrollo e implicaciones morales- de escritura ante una situación maravillosa es el del caballero de Irlanda, que cae defenestrado desde una torre. Situado al comienzo de la Demanda [7 f. 98v], mientras los caballeros aguardan a que suceda una maravilla para poder comenzar a comer, el caballero cae mientras arroja fuego desde su interior y de sus manos se desprende un texto. Después de varios sucesos, el rey Artur recuerda al caer la noche «la maravilla que viera del cavallero que ardiera, e preguntó quién avía las letras de aquel que cayera, que tenía en la mano»:

Y el rey tomó las letras, e leyolas, e falló que dezían: “¡Ay, arçobispo de Contúrber, hombre santo e de buena vida, e sesudo! Consuélame en mi mala vida e mala ventura, y en mi pecado, assí como yo te contaré. Sabe verdaderamente que yo lo descubro a Dios e a ti, que yo soy más pecador de los pecadores, que dormí con mi madre e con mi hermana, e después matéelas ambas en una hora porque no querían cumplir mi voluntad. E después, yo estándolas mirando do las matara, sobrevino mi padre, el rey de la Ínsola del Puerto. E después que vio aquella muerte, metió mano a su espada, e yo metí mano a la mía, e matelo. E do estava mirando, vino mi hermana y el conde de Gonon e maltrúxome, e yo matelo. E todo este

${ }^{32}$ Dirigida al arzobispo de Canterbury, llega finalmente a manos del rey Artur. El Prof. Contreras considera el episodio un encuentro especular similar al de Mereugís, pues explica el pasado del caballero: "es posible distinguir entre 'encuentros especulares' informativos o descriptivos, que aluden al pasado o al presente (EEI); y 'encuentros especulares' anticipativos, que predicen el futuro (EEA)», junto con sueños y visiones. Antonio Contreras, Anuario de estudios medievales, 40/2 (julio-diciembre 2010), pp. 925-935; las citas en pp. 926 y 929. 
mal que yo te digo, he fecho en un solo día. Agora me conseja, padre señor, ca tan grave penitencia no me darás que no la tenga".

E todo esto estava en las letras que'l cavallero tenía cuando murió. E desque el rey leyó las letras, ansí que las oyó Galaz e los altos hombres que con él estavan.

-Agora podemos saber por qué este cavallero murió tan crudamente: sabed que esta maravilla fue vengança de Jesucristo.

E los otros dixeron que bien parecía verdad, según lo que las letras dezían. Estonce fizo el rey guardar las letras en un almario de tesoro de santo Estiano de Camaloc, e fizo fazer rico monumento al cavallero; y escrivieron encima: “Aquí yaze el cavallero que'n un día mató a su padre, e su madre e sus hermanas". Este escrito fue fecho después que los de la Mesa Redonda fueran a la Demanda del Santo Grial. [31, f. 102v]

El pasaje pone de manifiesto la relación entre escritura y maravilla, y revela además los elementos de los procesos de transmisión y de fijación de los sucesos dignos de memoria. Algunos de estos elementos constitutivos se reiteran de forma habitual: que uno de los caballeros esté alfabetizado (además del rey Artur, lo están numerosos caballeros, como Merengís, Galván, Tristán, Lanzarote, etc.); que se dé a conocer el resultado de un suceso a través de la lectura; que la lectura se realice en voz alta, convirtiéndola en una fuente de información colectiva; que el rey ordene guardar estos textos en un almario para construir posteriormente un relato verídico basado en estos testimonios episódicos o, en otras ocasiones, que se escriba sobre una tumba el epitafio que preserve la memoria del caballero y narre al lector el motivo de su ventura. En última instancia, la duplicidad del mensaje conservado, en papel y en piedra, permitiría corroborar la veracidad de las microhistorias que entrelazadas construyen la gran historia de los caballeros. Mientras las líneas principales de los principales personajes parecen predestinadas por la Ventura, los secundarios optan por realizar acciones derivadas de su situación en el linaje y en la trama, que sirven de lección y subrayan los trazados narrativos fundamentales. El motivo de la lectura pública podría parecer estereotipado y común, un recurso combinatorio más en la trama. Sin embargo, los motivos de lectura y escritura, las elecciones dentro de su variedad, se encuentran aquí y allá aportando una precisión mayor en el tejido narrativo. Su inclusión informa del contexto de los sucesos y puede justificar y desencadenar al mismo tiempo complejas cadenas de acciones.

Los textos franceses, especialmente la Queste del Saint Graal, como analizó Todorov, se desdoblan en maravillas y acciones en el ámbito terrenal, que tienen un trasunto simbólico que no alcanzan a descifrar los caballeros. Los caracteres que participan en la urdimbre del texto no comprenden por sí propios la arquitectura causal y temporal en que se hallan envueltos. La aparición de ermitaños y hombres santos que 
explican el sentido último de las aventuras permite la revelación de su significado último en el plano espiritual. Las explicaciones de los ermitaños, el adoctrinamiento continuado de Galaz que lleva a cabo Nacián sobre su linaje y su destino a lo largo de las primeras aventuras, el envío de mensajes a través de mandaderas, el consejo de los caballeros, toma la comunicación oral como manera preferente. El lector no asiste al mensaje en su conjunto, sino a un resumen y a los efectos que desencadenan: formación y autoconsciencia en Galaz, comprensión de sueños, maravillas y visiones; revelación de acciones pecaminosas, etc. Precisamente, una de las características en las traducciones castellanas del conjunto del Pseudo Boron no se debe solo a la amputación de la mayor parte de las explicaciones simbólicas en el plano religioso, sino a la supresión casi por completo del segundo plano simbólico de la narración, otorgando al conjunto un sesgo marcadamente caballeresco y una religiosidad simplificada, que es especialmente marcada en la Demanda castellana ${ }^{33}$. La amputación de parte de estos contenidos pone ante los ojos del lector de una forma descarnada la incoherencia de algunas conductas individuales, pero también la información que se transmite mediante la escritura y su relación con la memoria colectiva.

\subsection{Las escrituras sagradas}

En diferentes ocasiones se mencionan las escrituras maravillosas como señales celestiales, que aclaran el significado de los sucesos a los que se asiste en el relato, y a las Sagradas Escrituras como fuente de verdad y de conocimiento último. Los episodios principales menudean especialmente en el José de Arimatea y la Demanda, donde es habitual asistir al combate entre las fuerzas del mal (diablos, malvados, encantadores) y la Providencia. Así, por ejemplo, ante el «santo yantar» nos encontramos la aseveración de una intervención angelical cuyo objeto es la explicación de la escena descrita:

E hincaron los doze compañeros e semejoles que venía un hombre todo revestido como obispo que quiere dezir missa. E traía una corona de oro en la cabeça muy rica, y en las manos muy ricos guantes. E traíanlo cuatro ángeles en una catreda de oro; y a la siniestra parte estava una mesa de plata en que estava el Santo Grial cubierto de xamete bermejo. E assí lo pussieron los ángeles sobre la cátedra, e tenía en la frente letras que dezían: «Yo só Josephés, el primero obispo del mundo y el que primero entró en la cibdad de Sarrás». [Demanda 375, f. 177r]

\footnotetext{
${ }^{33}$ José Ramón Trujillo, «Traducción, refundición y modificaciones estructurales en las versiones castellanas y portuguesa de La Demanda del Santo Grial», e-Spania, 16 (2013). En línea. DOI: https://doi.org/10.4000/e-spania.22919.
} 
Cardona se refiere a «un terror sagrado por estos símbolos y por su poder, como si una vez trazados, los símbolos pudiesen, por sí solos, desencadenar su acción $»^{34}$. Más allá de esta evidencia esperable, encontramos el caso aún más característico, que es el de las letras que surgen por origen divino e informan a la corte de Camaloc. Así sucede en el caso de uno de los objetos maravillosos por excelencia: Arturo conoce gracias a las inscripciones maravillosas quiénes son los destinados a ocupar un puesto en la Tabla Redonda y si su vida se ha apagado. Veamos a continuación tres ejemplos significativos:

Y ellos, que ya oyeran missa, fuéronse al palacio e avino que entrando e andando las sillas de la Tabla Redonda, fallaron: «Aquí deve ser fulán, e Aquí, fulán». E cuando llegaron a la Silla Peligrosa, fallaron ý letras nuevamente fechas que dezían: «A cuatro cientos e cincuenta e cuatro años complidos de la muerte de Jesucristo, en día de Pentecosté, deve aver esta silla señor». [6, f. 98r]

El rey Artur, que sin falta tanto amava a los de la Tabla Redonda como si fuessen sus fijos, e avía muy gran pesar porque se partían d'él. E por esto avía gran sabor por saber cómo les iva, e por esto iva cada día, ante que comiesse, a las sillas de la Tabla Redonda, e contávalos. Y cuando aí llegava, él veía en las letras si era bivo el señor d'ella, ca si era bivo fallara aí su nombre, e si era muerto no fallavan aí letra ninguna. E sin falta la Tabla Redonda era tan maravillosa que, en cualquier lugar, cuando alguno, cerca o lexos, moría, luego se quitavan ende las letras. [181, f. 133v]

Estonce loó mucho Éstor a Merengís de bondad de armas, e dezía mucho bien d'él a cuantos le preguntavan aquel día. E rogaron a Éstor el rey y la reina que fincasse con ellos algunos días. E otro día, a hora de mediodía, cuando el rey venía de missa, assentose en su palacio e vino ante'l uno de los clérigos que avía de escrevir el libro de las cavallerías de los cavalleros andantes, e fincó los inojos ante el rey, e díxole:

- Señor, si vós quisierdes, yo vos mostraré una cosa con que vos plazerá.

-Pues mostrádmela -dixo el rey.

- Señor-dixo él-, pues creednos.

Estonce se fueron ambos a la Tabla Redonda, y en la silla que solía ser de Erec, fallaron letras nuevas que dezían: «Aquí deve ser Merengís de Norgales». E cuando el rey vio las letras e las leyó, llamó a Éstor e a otros muchos cavalleros, e mostrógelas, e díxole:

- ¿Qué vos parece d'esta aventura?

Y Éstor, que mucho amava a Merengís que fue mucho alegre d'esta aventura, fabló primero, e dixo:

-Parésceme que ha ganado la honra de la Tabla Redonda este mi compañero, ca estas letras vos lo muestran. [186, f. 134v]

\footnotetext{
${ }^{34}$ Giorgio Raimondo Cardona, Antropología de la escritura, op. cit., p. 147.
} 
La escritura hace de la Mesa Redonda una reliquia sagrada, instrumento de la escritura celestial que sanciona la valía y revela la ventura de los caballeros en lo esencial: su ascenso a la caballería que iniciará la búsqueda del Grial, así como su fin en pos del milagro de la revelación.

\section{LA EMERGENCIA DE LA ESCRITURA EN LA COMPOSICIÓN}

\subsection{Escritura, voz narrativa y juego de planos}

Como es bien sabido, las coplas de octosílabos fueron la forma habitual en los romans franceses a finales del siglo XII. Su evolución constructiva y sus dimensiones parecían haber alcanzado sus límites expresivos, cuando la llegada de la prosa supuso un enorme progreso desde el punto de vista técnico, al permitir el abandono del cauce estrecho y artificioso del verso, sometido a unidad rítmica, sintáctica y semántica, y del valor repetitivo de la rima. La prosa permitía además acercar a la ficción, desde el punto de vista de la verosimilitud, a la credibilidad de la historiografía y de las escrituras bíblicas. El desarrollo de la prosa novelesca, parejo a la consecución de sus logros técnicos, fue lo que permitió a lo largo de la primera mitad del siglo XIII su indudable éxito y extensión. Frente a la lectura constante del verso y su disposición monótona en el pergamino, frente a la singularidad e independencia de cada obra, los manuscritos en prosa ofrecían al lector unos recorridos visuales novedosos. Los textos constituían grandes conjuntos de infolios en los cuales las unidades narrativas se disponían en apartados localizables por grandes capitulares, de manera que el ojo del lector podía comprender la articulación esencial y efectuar una recuperación del tempo del relato para adecuarlo al tempo de la lectura. Las iluminaciones, rúbricas y blancos ordenaron estos nuevos caminos del ojo en la lectura, mientras los prólogos, epílogos y marginalia relacionaban de manera eficaz las ramas y divisiones mayores de los grandes conjuntos. El copista-refundidor descubre de esta manera los procesos para convertir en ciclos los conjuntos de secuencias autónomos ${ }^{35}$.

El transcurso del siglo XIII es, también, el momento del tránsito desde la escritura al dictado -que aún reconocemos tematizados en algunos pasajes y miniaturas artúricas- a la generalización de la escritura directa $^{36}$. Las nuevas formas de trabajo adquieren la forma de una voz textual consciente, que emerge en algunas páginas escogidas. Desde el prólogo y a lo largo del texto, sobre esta extensión segmentada del

${ }^{35}$ Elspeth Kennedy, «The Scribe as editor», en Mélanges de langue et de littérature du Moyen Age et de la Renaissance offerts à Jean Frappier: professeur à la Sorbonne, Genève/ Paris, Droz/Minard, 1970, pp. 523-531.

${ }^{36}$ Monique Bourin-Derruau, Nouvelle histoire de la France medievale. Vol. 4, Temps d'équilibres, temps de ruptures / XIII' siècle, Paris, Editions du Seuil, 1990, pp. 32-36. 
roman artúrico, una voz narrativa acompaña al lector, en ocasiones de manera silenciosa, en otras, en alta voz y en diálogo abierto. En el roman en prosa, que imita y emplea los recursos de la escritura bíblica, la voz narrativa organiza el discurso, reclama la veracidad de los hechos, introduce las partes y engarza mediante fórmulas estereotipadas ( Or dit li contes», "Agora dize el cuento») las unidades narrativas de diferente extensión y alcance. La voz anónima de la Suite du Merlin recoge la narración dictada por Merlín a Blaise; este último, el «hombre bueno» del Baladro, se encarga de poner los hechos por escrito, lo que introduce la sensación de veracidad mediante la superposición de niveles de la narración (Merlín el profeta habla, elucida, adelanta el destino; Blaise recoge directamente las palabras y las consigna en la forma en prosa de la crónica y de la escritura sagrada; Robert de Boron reproduce fielmente el texto de Blaise; el trasladador, clérigo copista o traductor, copia desde el libro heredado: ordena y valora, acerca al lector). El yo que habla en el texto no es identificable con el autor: se trata ahora de un transmisor de un texto recogido en un tiempo pasado por una voz autorizada. Un intermediario que no desea intervenir y que incluso se muestra incapaz de repetir lo que no se ha recogido previamente, pero que en ocasiones ha de tomar partido, resumir o censurar el texto heredado. Se trata de la acuñación del tópico de la traslación de un texto autorizado que recoge hechos reales narrados por un observador.

El afinamiento como técnica de este sistema de múltiples niveles se produce en el desarrollo de la arquitectura del Lancelot-Graal, un ciclo que deriva en última instancia de la recogida de las proezas de Lancelot y del resto de compañeros de la Tabla Redonda, del acopio de testimonios parciales realizada en vivo por testigos presenciales a los clérigos del rey Artur, de donde se explica su fragmentación y su falta de totalidad. Este recurso será el mismo que se empleará en la Queste, tal y como se refleja en su final:

Quant il orent mengié, li rois fist avant venir les clers qui metoient en escrit les aventures del Seint Graal telles come il les avoit veues, si furent mises en escrit et gardees en l'almiere de Salesbieres, don't Mestre Gautier Map les trest a fere son livre del Seint Graal por l'amor del roi Henri son seigneur, qui fist l'estoire translater de latin en françois. Si se test a tant li contes, que plus n'en dist des Aventures del Seint Graal. [Queste, 279-280]

Todos los textos artúricos ${ }^{37}$ son siempre traslaciones y la voz narrativa que en ellos habla al lector le confirma que está ante un texto veraz, que

${ }^{37}$ El Tristan en prosa, aun valiéndose del mismo tópico, declara que su autor es un caballero «amoreus et envoisiez», lo que permite una escritura profana. Nos encontramos ante la fuente misma del sistema que reproducen casi todos los libros de caballerías y que, en forma 
narra hechos comprobados recogidos a lo largo mismo del desarrollo de las aventuras, de forma coetánea; que no existe distancia -salvo la del tránsito por el papel o de una a otra lengua- entre lo que lee u oye y lo que los héroes han leído y escuchado. Esta técnica construye un espacio que intermedia entre la voz autorizada que emerge en el texto y su lector/ oidor. Genera un espesor en la narración que multiplica la verosimilitud, afirma su historicidad y potencia el ejemplo didáctico que debe extraerse.

Como no podía ser de otra forma, en la Demanda castellana se observa el recurso a la misma técnica. Los personajes se encuentran acuciados por narrarse sus historias, porque se recuerde su esfuerzo y su paso por la tierra. El rey Artur se preocupa de manera constante de que se recojan por escrito todas las aventuras - de forma fragmentaria u ordenada- y de que se custodien y preserven convenientemente para su ulterior empleo en la redacción de la gran historia: «Estonce fizo el rey guardar las letras en un almario de thesoro de santo Estiano de Camaloc» [31, f. 120v]; «e cuanto la boz le dixo fízolo meter en un almario del tesoro de la Silla de Camaloc» [288, f. 156v]; «E tanto que el rey Artur lo supo, hízolo escrevir en el Libro de las aventuras» [344, f. 168v]; «E fizo él escrevir esta aventura con las otras» [357, f. 171r].

Quienes esto realizan son los propios clérigos de Camaloc, omnipresentes en la fase de traslado desde el recuento oral de las aventuras a su fijación en prosa en pergaminos. Bajo la supervisión directa del rey, tienen como encargo la consignación fehaciente del recuerdo y su redacción para preservarlo del paso del tiempo, para convertirse en base de una crónica integrada de la era de las maravillas antes de su ocaso: «E otro día, a hora de mediodía, cuando el rey venía de missa, assentose en su palacio e vino ante'l uno de los clérigos que avía de escrevir el libro de las cavallerías de los cavalleros andantes» [186, f. 134v].

De igual modo, se dejan por escrito las aventuras individuales de los que caen en el Lanzarote y la Demanda. Se tallan sobre las sepulturas los hechos y los nombres de cuantos intervinieron en ellas; sirven de hitos para reconocer una geografía heroica y los lazos del linaje, como sucede en el episodio de Lanzarote en la tumba junto a la Fuente hirviente [LancelotGraal, BNF fr. 113, f. 116r]. Según Baumgartner ${ }^{38}$, el término «historia» (estoire) -la «verdadera historia» de la Demanda- indica en la Queste la fuente escrita que se sigue en la narración y podría referirse a los textos que los clérigos han ido consignando a lo largo de las aventuras o la que han ido dictando Boorz y los otros caballeros. Este conjunto de textos, la «verdadera historia» cercana a los sucesos acaecidos realmente, la historia, en una segunda instancia se han traducido y convertido supuestamente en libro por obra de Walter Map, convertido a su vez en autor del relato

de parodia en la figura de Cide Hamete Benengeli, permite la construcción de la profundidad a través de múltiples planos en el Quijote.

${ }^{38}$ La Quête du Saint-Graal, Emmanuèle Baumgartner (tr.), Paris, Champion, 1983. 
ordenado de la Queste. En cuanto al término «cuento» (conte, en francés), «il est a l'instance énonciative de cet énoncé. Ainsi est constituée une tradition écrite qui relie sans discontinuité l'événement -les aventures- et leur relation, le texte de la Queste et permet donc d'en garantir l'authenticité, la veracité $\rangle^{39}$. En el texto castellano se denomina el Libro de las Aventuras a la crónica que registra los principales sucesos acaecidos a los compañeros de la Tabla Redonda, que el rey Artur ordena poner por escrito según van sucediendo. Se trata del segundo plano, el más próximo al relato oral de los hechos por testigos, cuyo carácter se pretende historiográfico. En la Demanda, sobre esta voz autorizada en latín trabaja el supuesto Boron organizando estas crónicas redactadas por los clérigos de Artur, dispersas o fragmentarias, disponiendo las secuencias de las aventuras en francés. Se trata del tercer plano, intermedio, que ordena temporalmente y entrelaza artísticamente las aventuras, aunque supuestamente sin intervenir en ellas. Sobre el cuento del Pseudo Boron actúa en un cuarto plano, ahora supuestamente en castellano, el traductor-refundidor hispánico, cuya voz aparece en el texto para anunciar alteraciones sobre el original que refunde.

Veamos como muestra de este plano el siguiente ejemplo, que se produce tras dar la lista de los veintiún muertos habidos en determinado momento durante la búsqueda:

Estos fueron muertos en la Demanda del Santo Grial. Mas no vos diré más agora, ca ya devisado lo ha el cuento cómo murieron; e los otros fallé en francés e no lo escreví en castellano; mas habla la gran historia de Llain de cuanto yo cuento [Demanda 194, f. 136v]

Todos estes foram mortos na demanda do Santo Graal, mais nom vos direi como ca o nom achei em francês, nem Boirom nom diz que em mais achou na grande estória do latim de quanto eu vos conto [A Demanda do Santo Graal, f. 121b]

Sommer consideraba un error estas alteraciones entre versiones ${ }^{40}$. Pero más que el error concreto de traducción que ayuda en la determinación de un supuesto arquetipo, lo que verdaderamente resulta esclarecedor en el pasaje, la cuestión pendiente más allá de la disputa sobre el sentido de las traducciones dentro del corpus románico ${ }^{41}$, es entrever en

${ }^{39}$ La Quête du Saint-Graal, Baumgartner (tr.), op. cit., n. 17, pp. 248-249.

${ }^{40}$ «There is a hardly any doubt that do latin (for em latim) instead of de Llayn, i.e. Alain, or Helain le blanc, the son of Boors de Gaunes is another blunder in $P \gg$. Heinrich Oskar Sommer, «The Queste of the Holy Grail forming the third part of the trilogy indicated in the suite du Merlin Huth», Romania, 36 (1907), pp. 369-402 y 543-590; la cita en p. 562. Para un compendio de los problemas que plantea la traducción medieval, vid. Joaquín Rubio Tovar, «Algunas características de las traducciones medievales», Revista de Literatura Medieval, 9 (1997), pp. 197-243.

${ }^{41}$ La noción de prioridad ha suscitado un sinnúmero de publicaciones. Vid. Manuel A. Rodrigues Lapa, «Demanda do Santo Graal. Prioridade do texto português», A Língua Portuguesa, 1 (1929-1930), pp. 266-279 y 305-316; separata, Lisboa, Seara Nova, 1930; y el resumen actualizado de la situación en José Ramón Trujillo Martínez, «Literatura artúrica en la Península 
algunos de estos cambios la intención de quien trabaja con el texto, cuál es la valoración del concepto autorial ${ }^{42}$, los niveles de intervención y la proyección de la materia artúrica hacia un futuro inmediato. Fijarse en el telar y sus técnicas, sus variaciones, y no exclusivamente en el modelo, de manera que podamos comprender las recepciones sucesivas a las que van dirigidas. Aun manteniendo ambos textos una estrecha relación, se observa -como en otras emergencias del traductor castellano- una diferencia significativa en el propósito y en la ideología de su actuación sobre los materiales que se transcriben. Mientras el traductor gallegoportugués declara mantenerse fiel al original francés, advirtiendo que Boron no tradujo más del latín, el texto toledano declara que voluntariamente no traduce del francés al castellano y remite al lector-como en otras ocasiones- a la historia de (He)Laín. Es decir, reclama la autoría del refundidor sobre las intervenciones ${ }^{43}$.

En resumen, una sucesión de trasladadores y traductores transmiten el texto sin intención de intervenir en él -salvo por los errores y las deturpaciones habituales-, pero también aparecen refundidores, cuya intención es modificarlos conscientemente y se sienten autorizados para ello. Encontramos entonces nuevos planos -quintos, sextos...-, en los que la voz del nuevo coautor se superpone y modifica a los anteriores, reconstruyendo el texto para que alcance a un público nuevo. El refundidor posee un estatus diferente al de simple traductor, pues este se muestra cercano en funciones y errores al copista. El refundidor actúa conscientemente sobre los materiales heredados, moviéndose con libertad por el espacio construido entre el supuesto escrito histórico y el texto que el lector-oidor maneja, reordenando e interviniendo desde su propia voz autorial, aunque ahora dentro de la ficción, más cercana al entretenimiento que a la imitación de la historiografía o de los textos religiosos. Esta sucesión de planos otorga una complejidad ficcional tal que genera un espesor de vida paralelo al espesor temporal generado por el entrelazamiento, aunque no siempre sea coherente. El texto se despliega y vuelve a contarse ante el lector-oyente, jugando con su complicidad.

Ibérica: Cuestiones traductológicas y lingüísticas», eHumanista, 28 (2014), pp. 487-510. En línea: <https://www.ehumanista.ucsb.edu/sites/secure.1sit.ucsb.edu.span.d7_eh/files/sitefiles/ehumanista/volume28/ehum28.mon2.trujillo.pdf $>$ [consulta: 7/07/2019].

${ }^{42}$ Por ejemplo, para Carter, el traductor hispánico del El livro de José de Arimateia es solo un «mysterious fourteenth-century friar-scribe», mientras que para Lida de Malkiel, los textos castellanos carecen de originalidad y son de escaso valor literario al predominar en ellos la acción caballeresca. Henry Hare Carter, The Portuguese Book of Joseph of Arimathea, Chapell Hill, University of North Carolina, 1967, p. 39. M. ${ }^{\text {a }}$ Rosa Lida de Malkiel, «Arthurian Literature in Spain and Portugal», op. cit., pp. 406-418. Las ediciones con criterios científicos que se han llevado a cabo en las últimas dos décadas deben permitir una revaluación de las obras a partir de los nuevos conocimientos adquiridos sobre ellas.

${ }^{43} \mathrm{Vid}$. el cotejo y estudio del fragmento en José Ramón Trujillo Martínez, «Yo, Joannes Bivas: la emergencia de la voz del traductor en la Edad Media», en Aviva Garribba (ed.), Rumbos del hispanismo en el umbral del Cincuentenario de la AIH, Roma, Il Bagatto Libri, 2012, vol. II, pp. 370-381. 
Junto a la mención de la historia, el sistema formulario de fragmentación del texto recurre a la mención del «cuento». Por contraposición a la «historia», la voz «cuento» indica una relación basada netamente en la oralidad y el hilván episódico ${ }^{44}$. Sin embargo, el relato oral tradicional, aunque conoce la técnica, no es capaz de entrelazar numerosas unidades narrativas en una estameña de tal complejidad, ni tampoco desarrollar una amplia panoplia de actantes ${ }^{45}$, pues se encuentra constreñido por los mecanismos estéticos y las limitaciones impuestos por la memoria ${ }^{46}$, ámbito en el que juega con ventaja el verso, una tecnología desarrollada expresamente al efecto. La especificidad del texto artúrico en prosa radica en el carácter que adquiere el texto de soporte de una «performance», pero también para facilitar la lectura y la relectura autónoma de episodios ${ }^{47}$. Los términos de la dicción y la audición, no de la escritura, son los relacionantes entre el lector-auditor, el autor y la propia obra; un sistema para la «navegación» del texto, que afecta a todos los planos, tanto de creación como de reproducción. Una voz que tutea al público, que anuncia o remite dentro del texto o a otros textos: «e cuando vino al tercero día do andava assí pensando, apareciole un diablo assí como vos diré» [156, f. 128v]; «El tercer día, como vos digo, le avino que aquel que avía nombre Nabor» [157, f. 128v]. Un público receptor que quien redacta sabe oyente más que lector, lo que afectará a sus estrategias textuales: «E sepan todos aquellos que este cuento oirán que aquel Helaín el Blanco fue fijo de Boores de Gaunes» [12, f. 99r].

${ }^{44}$ El Amadís prefiere el engarce «"dexa la historia” frente al “dexa el cuento” más utilizado en la tradición artúrica. Esto puede significar una conexión con la historiografía». Juan Manuel Cacho Blecua, «El entrelazamiento en el Amadis y en las Sergas de Esplandián», en Studia in Honorem Profesor Martín de Riquer, Barcelona, Quaderns Cremá, 1986, pp. 235-271 (esp. p. 244). La Gran Conquista de Ultramar también prefiere el empleo de «torna la historia».

${ }^{45}$ Todorov afirma que la literatura no es capaz de alcanzar la alternancia. Esta posición es exagerada. La alternancia existe en la oralidad, aunque tiene como límites la memoria del contador y del oidor. Tzvetan Todorov, Literatura y significación, Barcelona, Planeta, 1971, p. 92. Según Havelock, la tecnología de la memoria basada en el almacenamiento escrito no supuso en época clásica un rival para «la tecnología lingüística consagrada del almacenamiento oral dominado por los rapsodas profesionales» basada en un amplio espacio público, una dignidad ritual y un eco funcional y emocional inmediato en su auditorio. Durante siglos la oralidad convive con las inscripciones epigráficas. Eric A. Havelock, La musa aprende a escribir. Reflexiones sobre oralidad y escritura desde la Antigüedad hasta el presente, Barcelona, Paidós,1986, p. 122.

${ }^{46}$ Eugène Vinaver, A la recherche d'une poétique médievale, Paris, Nizet, 1970, p. 133.

${ }^{47}$ Zumthor pone de relieve la dificultad de entender las obras antiguas desde el punto de vista del lector contemporáneo, ya que éste ha perdido la noción de una obra que sucede -performance-. Es cercana en esto al teatro, pero, a diferencia de éste, se produce, reelabora continuamente y conserva sólo a través de la oralidad. Paul Zumthor, La poésie et la voix dans la civilisation médiévale, Paris, PUF, 1985, pp. 37-40 y 42-49. Para las relaciones de la creación y la oralidad, vid., además Paul Zumthor, La poésie orale: Introduction à la poésie orale, Paris, Du Seuil, 1983, pp. 115-149 y 209-227; Jan Vansina, La tradición oral, Labor, Barcelona, 1967, pp. 53 y ss.; y Cécil Maurice Bowra, Poesía y canto primitivo, Barcelona, Antoni Bosch, 1984. Para la recepción, vid. las iluminadoras páginas de Margit Frenk, Entre la voz y el silencio, Alcalá de Henares, Centro de Estudios Cervantinos, 1977, pp. 7-38 y 47-56. 
Havelock indicaba para la paulatina sustitución en el ámbito griego de la oralidad por la escritura que «un acto de visión se ofrecía en lugar de un acto de audición como medio de comunicación y como medio de almacenamiento de la comunicación. La adaptación que provocó fue en parte social, pero el mayor efecto se hizo notar en la mente y su manera de pensar mientras habla» ${ }^{48}$. Si así fuera y pudieran extrapolarse sus conclusiones, el conjunto de estrategias textuales artúricas en prosa revelarían la persistencia de la oralidad, su valor declamativo y sus propiedades de coloración emocional en una sociedad no oficial ni mayoritariamente alfabetizada, potenciada quizá por la lectura pública de fragmentos y episodios, mientras que las condiciones de organización narrativa responden a unas tecnologías de la memoria escrita plenamente desarrolladas y potenciadas a su vez por la influencia de la escritura histórica y sagrada y por la presencia material del papel.

La complejidad del recurso se aprecia en la urdimbre de las diferentes tramas. Un tipo especial de ordenadores textuales formularios son las remisiones a otros pasajes adelante y atrás, o a otros textos del acervo, que nos muestran el índice de conciencia autorial del proceso de escritura:

«E cuando el rey llegó a la ribera, e vio el padrón e la espada aí metida por el encantamiento de Merlín, assí como el cuento lo ha devisado» [8]. «E la otra silla fue de un cavallero d'Escocia que avía nombre Danarín, que matara Tristán en aquella demanda ante la Joyosa Guarda, porque aquel Danarín demandara su amor a la reina Iseo, mas esta aventura no dirá la historia del Sancto Grial, ca no [a]tañe al su libro mas la gran historia que llaman de Tristán lo devisara» [11]. «E la donzella, sin falla lleváronla, que la no pudieron levar, ni el cuento no dize más della, mas diz del cavallero que fue soterrado aí» [60]. «Mandas, el de la silla mal tajada, de que el cuento del Bastardo fabla mucho» [36]. "Y este escudo es el que'l rey Mordraín traxo en la batalla con el rey Tolomer, onde tú ya oíste el cuento» [49]. «Y estonce le comiençó a divisar la historia del escudo, assí como el cuento lo ha devisado. E lo que vos ya dixe, no vos lo quiero otra vez contar» [49].

Las marcas formales permiten al lector localizar con rapidez y efectividad el final de una historia y el arranque de la próxima - «Dize el cuento que», «Agora dexa el cuento a $[\ldots]$ e torna a $[\ldots] »-$; es decir, mantener una comunicación permanente con el lector-oidor y actuar sobre la lectura a través de la vasta selva de las aventuras, combinado con otras estrategias visuales como las rúbricas, capitulares, ornamentos y miniaturas. $\mathrm{Su}$ empleo enlaza la escritura con la oralidad, cerrando o proyectando entre sí numerosas cláusulas sin permitir los extravíos del que escucha en lugar de leer con los ojos, y acerca el texto original mediante la cercanía de la

\footnotetext{
${ }^{48}$ Eric A. Havelock, La musa aprende a escribir, op. cit., p. 137.
} 
voz que emana del mismo texto, lo que permite acceder a la interpretación de la voz de los personajes de las secuencias dialógicas.

La fuente original y remota en latín -supuesta en el fondo de las diferentes capas autoriales- garantiza la autenticidad y veracidad, por lo que la cercanía en la interfaz textual más cercana al lector/oidor permite emplearse en asegurar la sensación de inmediatez. Este sistema de incisos en tercera persona elimina a la primera persona, al narrador, poniendo directamente en primer plano al propio texto, que es quien se narra a sí mismo desde su autoridad, quien habla sin intermediarios proporcionando objetividad. El sistema facilita, como al contemplar el agua a través de un río, ver al mismo tiempo las sucesivas reelaboraciones y mantener, aunque deformado, el reflejo del original sobre la superficie de la lectura en su reelaboración más cercana. Conforme la transmisión se hace más compleja o existen más cambios de lenguas o de épocas, algunas formas del fondo van quedando oscurecidas. El sistema es explotado hasta el punto de que en ocasiones los mismos personajes asisten a la escritura de la propia historia - en la escritura mágica de la Tabla Redonda o en la voluntaria de las sepulturas y escrituras que se redactan en Camaloc- y opinan acerca de su desarrollo:

Estonce se fueron ambos a la Tabla Redonda, y en la silla que solía ser de Erec, fallaron letras nuevas que dezían: "Aquí deve ser Merengís de Norgales». E cuando el rey vio las letras e las leyó, llamó a Éstor e a otros muchos cavalleros, e mostrógelas, e díxole:

— ¿Qué vos parece d'esta aventura? [Demanda 186, f. 134v]

Sin embargo, aunque el texto se diga a sí mismo, aunque los personajes comenten su propia historia, el narrador no termina de desaparecer completamente, sino que adopta formas diferentes correspondientes a diversos planos y puntos de vista. Incluso aparece en algunas ocasiones para intervenir deliberadamente y mediante mecanismos propios de la oralidad. El cambio de la voz del narrador - que en una forma de ventriloquismo puede ocultar autores, refundidores y traductores- por expresiones formularias, convierte en muy significativos los pasajes en que este emerge hablando de sí mismo y de su labor, porque son aquellos en los que anuncia su traición al texto fuente, en los que expresa el carácter de su intervención sobre la herencia, para resumir, incorporar o suprimir unidades narrativas. Para resemantizarlo y conectarlo con un nuevo auditorio y unos nuevos intereses.

\subsection{Entrelazamiento y alternancia}

El paso desde la oralidad hacia la escritura es evidente y sus consecuencias ficcionales irrenunciables, aunque en todo momento se observa 
la emergencia de aquella en esta. No es solo la presencia de la escritura y la lectura como motivos recurrentes, se trata de la liberación del libro de la linealidad a la hora de narrar la «historia», algo que solo la escritura en prosa permite de manera definitiva. Los engarces de episodios son, en el plano temporal-estructural, cicatrices de la composición de secuencias, en las que se producen las largas elipsis o los saltos temporales hacia atrás para reproducir en el tiempo textual su sincronía. La narración consiste en disponer una serie de secuencias unidas lógicamente por unas relaciones de solidaridad entre ellas, que pueden constituirse de forma lineal o intercalándose sobre la linealidad temporal. Frente a la estructura narrativa lineal, marcada por un héroe que sirve de hilo conductor en sus diferentes aventuras, el empleo sistemático de las fórmulas descritas permite narrar de manera sincrónica múltiples acciones paralelas, construyendo a partir de episodios dejados anteriormente en suspensión o del inicio de nuevos ${ }^{49}$. Ampliar infinitamente el espacio de la narración, como una manifestación de la libertad creadora:

La forme du récit est essentiellement marquée par deux pouvoirs: celui de distendre ses signes le long de l'histoires, et celui d'insérer dans ces distorsiosn des expansions imprévisibles. Ces deux pouvoirs apparaisent comme des libertés; mais le propre du récit est précisément d'inclure ces 'écarts' dans sa langue. [...] Distendus, les noyaux fontinels présentent des espaces intercalaires, qui peuvent être comblés quasi infiniment ${ }^{50}$.

Se trata de la conocida técnica de «entrelazamiento» posiblemente empleada por Chrétien para entretejer las historias de Yvain y de Gauvain, que sucedían de forma simultánea. Permite también ordenar las secuencias de manera alterna y secuencial, eliminando las unidades narrativas ininteresantes para el desarrollo del relato, lo que consiente

${ }^{49}$ El estudio fundacional sobre el entrelazamiento lo lleva a cabo Lot para el Lancelot. Ferdinand Lot, Étude sur le «Lancelot» en prose, Paris, Champion, 1918, cap. II, cito por la reimpresión de 1954. Se ha desarrollado con el paso del tiempo un fecundo corpus en varias lenguas. Emmanuèle Baumgartner ha analizado el entrelazamiento en el Tristan, Frappier en la Mort Artu y Lathuillère en el Guiron le Courtois. Vid. Emmanuèle Baumgartner, De L'histoire de Troie au Livre du Graal. Le temps, le récit, Orleans, Paradigme, 1994. Jean Frappier, Étude sur «La Mort le Roi Artu», Genève, Droz, 1961, pp. 347 y ss. Roger Lathuillère, «Guiron le courtois», étude de la tradition manuscrite et analyse critique, Genève, Droz, 1986. Disponemos de un análisis de conjunto de Ryding y realiza una síntesis actualizada de la cuestión en Carol S. Chase, «Sur la theorie de l'entrelacement: ordre et desordre dans le Lancelot en prose», Modern Philology, 80 (1983), pp. 227-241. Vid. William W. Ryding, Structure in Medieval Narrative [Mouton, 1971], reed. De Gruyter, 2011, DOI: https://doi.org/10.1515/9783111341255. Carol S. Chase, «Multiple Quest and the Art of Interlacing in 13th Century», Romance Quaterly, 33/4 (1986), pp. 407-420. DOI: https://doi.org/10.1080/08831157.1986.11000392. Para los textos españoles, vid. los trabajos de Weber y el fundamental de Cacho Blecua: Frida Weber de Kurlat, «Estructura novelesca del Amadis de Gaula», Revista de Literaturas Modernas, 5 (1967), pp. 29-54; Juan Manuel Cacho Blecua, «El entrelazamiento...», art. cit..

${ }^{50}$ Roland Barthes, «Introduction à l'analyse structurale des récits», Communications, 8 (1966), pp. 1-27 (cita en pp. 23-24). 
una gran complejidad estructural sin una pérdida de la coherencia del conjunto. El primer ejemplo lo ofrece Perceval, que narra las aventuras de Gauvain interpolándolas en el hueco narrativo que suponen los cinco años vacío de Perceval. Contrariamente a lo que puede pensarse, el hallazgo del entrelazamiento y la alternancia no se generalizó en la escritura medieval en prosa ${ }^{51}$. Esta siguió manteniendo las estructuras lineales, como en el caso del Joseph, el Merlin o la primera versión del Tristan en prosa, así como su preferencia por agruparse mediante marcos. Es el Lancelot de la Vulgata la obra que perfecciona el sistema y lo convierte en un principio constructivo de conjunto. El entrelazamiento consiste en narrar las aventuras sucedidas a varios caballeros de forma sincrónica durante un periodo concreto -por ejemplo, un año-, cortando la secuencia en momentos de clímax o anticlímax y haciendo que converjan o se separen en puntos determinados. Como hemos visto al hablar del eje narrativo, los entrelazamientos no son exactos, de manera que el cálculo de las unidades narrativas entrelazadas de Perceval y Boorz no permite que coincidan. En este orden de cosas, es necesario subrayar la voluntad de generar un tempo narrativo en el que la disposición de los episodios posee un orden preciso, pero no exactitud cronológica. Para Cacho Blecua: «El tiempo está en función de la aventura sin importar su precisión. El autor en los entrelazamientos solo pretende dar sensación de simultaneidades, no cronologías exactas $\rangle^{52}$.

El entrelazamiento es un salto cualitativo en las técnicas escriturarias, ya que consigue una sensación vívida del tiempo del relato y, por tanto, de realidad; permite una visión global de la materia y del espacio representado -y ampliarlo hasta alcanzar sus límites-; y la suspensión de episodios proporciona tensión y ritmo a la narración, es decir, la creación de efectos de suspense en el relato que configuran una visión sinóptica y plural de un cronotopo o tempoespacio narrativo ilimitado. Emmanuèle Baumgartner considera que el entrelazamiento

permet ainsi de donner au récit une sorte d'épaisseur temporelle, de substituer surtout au déroulement linéaire du temps, un temps répresenté (réprésentable autant qu'il y a de personnages engagés dans la séquence) dans un même présent dont le récit feint d'épuiser les possibles narratifs. Elle joue ainsi un rôle considérable dans l'élaboration d'une écriture qui se veut exhaustive et globalisante et qui semble à la recherche d'une durée propre ${ }^{53}$.

Precisamente la alteración del entrelazamiento es lo que cambia el discurso y su estructura y permite modificar su carácter con sencillez y

\footnotetext{
${ }^{51}$ Merlin. Roman du XIII ${ }^{e}$ siècle, ed. de A. Micha, Genève, Droz, 1980, pp. 150-151.

52 Juan Manuel Cacho Blecua, «El entrelazamiento en el Amadis...», op. cit., p. 247.

${ }^{53}$ Emmanuèle Baumgartner, De L'histoire de Troie au Livre du Graal, op. cit., p. 104.
} 
muy pocos recursos: suprimiendo y resumiendo pasajes, anticipando o recordando sucesos y linajes. El trabajo de refundición en castellano se centra de forma esencial sobre el entrelazamiento del texto traducido del Pseudo Boron, empleando estos puntos de sutura para eliminar unidades narrativas con el fin de ajustar la extensión o modificar y adecuar el espíritu del conjunto. La tendencia hacia lo caballeresco, advertida ya por Bohigas, la enunció de forma sintética Durán ${ }^{54}$.

Además del ciclo de La Vulgata existió otro, distinto y posterior, falsamente atribuido a Robert de Boron, del cual procede nuestra Demanda, y una de cuyas características más importantes es la de que su autor redujera la demanda del Graal al nivel de una simple aventura, profundizando así el proceso de desespiritualización iniciado en el Lancelot [...] la tercera parte [la Demanda], por último, fue aumentada en la extensión de más de un tercio del total, dándosele carácter caballeresco, que no se compagina bien con el fondo religioso de la obra ${ }^{55}$.

En su breve aproximación al empleo del entrelazamiento en la $D e$ manda en comparación con la Queste, Steiner advierte ${ }^{56}$ también, como lo hizo Moises para el texto portugués, que aquella pone «más énfasis en los aspectos externos» que en los religiosos y presenta un fresco dramático simultáneo. Para él

El método artístico de la Demanda castellana es estructural, no psicológico. Lo que se pretende hacer ver a través de hechos externos es la diferente forma de actuar en cada uno de los numerosos caballeros que salen en busca del Santo Grial. Como en una serie de retablos separados y poco coherentes entre sí, se quiere expresar de forma sincrónica -y no de forma lineal, cronológica y psicológica- las múltiples hazañas de los diversos caballeros.

Por otro lado, se fija en que el compilador castellano omite materia de la Queste, recurriendo al resumen: «El recopilador español omitió, sin

${ }^{54}$ Pere Bohigas, Los textos españoles y gallego-portugueses de la Demanda del Santo Grial, Madrid, Imprenta Clásica Española, Anejo VII de la RFE, 1925. Armando Durán, EStructura y técnicas de la novela sentimental y caballeresca, Madrid, Gredos, 1973, pp. 89-90.

${ }^{55} \mathrm{Al}$ mencionar la Demanda como origen de los procesos estructurales del Amadis y otras obras caballerescas, este crítico hace hincapié precisamente en el cambio de este espíritu: «La pérdida del simbolismo religioso, el gusto por las aventuras en sí, el carácter errante de la caballería y hasta un cierto sentido trágico del amor, serán los elementos más importantes en la elaboración de nuestros libros y novelas de caballerías». Armando Durán, Estructura y técnicas, op. cit., p. 92. Resulta insostenible, sin embargo, su conclusión de que «a España llegan unos materiales en los que los caballeros errantes se enfrentan a unas aventuras que han perdido tanto su valor ético inicial como su posterior simbolismo religioso, amplificadas y entrelazadas paratácticamente, sin un desenlace decisivo, y en las que el hijo del héroe continúa las aventuras del padre superándolo abiertamente», ibid., pp. 155-156.

${ }^{56}$ Roger J. Steiner, «La técnica narrativa de "entrelazamiento" en La Demanda del Sancto Grial», Revista de literatura, 38, núms. 75-76 (1970), pp. 141-146. 
duda, alguna que otra cosa, a fin de organizar la obra a su gusto». Precisamente esa «alguna que otra $\operatorname{cosa»}{ }^{57}$ que omite de manera sistemática el refundidor castellano son los pasajes simbólicos, en los que se expresan las senefiances, y las unidades narrativas protagonizadas por Perceval y Lanzarote, con el fin de disponer en dos planos paralelos la materia, con Galaz como referencia continua, y no en forma de fresco incoherente, como afirma Steiner. Desde el punto de vista de la estructura, el entrelazamiento es el recurso esencial, pero no consiste solo en imbricar una sucesión de actos externos para dar a conocer la personalidad de los caballeros, sino de un proceso consciente de jerarquización, que se produce de forma simultánea en dos planos claramente diferenciados, el cortés y el religioso $^{58}$, lo que jerarquiza a los caballeros de la Tabla Redonda según el tiempo y orden que se les concede, como en el caso del Lancelot, o mediante el carácter de la aventura y la eliminación del personaje del relato, como en el caso de la Queste, grado máximo de aplicación de la técnica.

\section{FINAL}

Las confluencias entre oralidad y escritura en las literaturas artúricas resultan un tema central y apasionante, que es imposible de agotar en la extensión de un artículo. Las obras traducidas incluyen centenares de eventos relacionados con la cultura escrita y sus usos. El manejo de diferentes niveles de escritura de lo acaecido en ellas permite un sofisticado trabajo de urdimbre y construcción narrativa. Es posible señalar varios usos de la lectoescritura en los textos. El primer nivel o funcional, cuya misión es asegurar la transmisión de información inmediata, no es prerrogativa masculina, sino que se encuentra extendida indistintamente entre caballeros, damas e infantes ${ }^{59}$. La artúrica es una aristocracia letrada en general, pero sus dinámicas informativas, demostrativas y deliberativas se apoyan fundamentalmente en la oralidad. La corte es una sociedad de opinión donde el renombre depende del linaje, pero también

${ }^{57}$ La conclusión general de Steiner de que la Demanda castellana prioriza las acciones externas es válida y coincide con Bohigas y Durán, a pesar de que ninguno aporte pruebas. En algunas afirmaciones, aunque cita uno de sus trabajos, Steiner revela desconocer completamente las conclusiones de Bogdanow, por ejemplo, de que algunos fragmentos de la Demanda siguen versiones variantes de la Vulgata y no haber manejado los textos franceses, portugueses ni la edición de 1515 .

${ }^{58}$ Esta duplicidad de planos la enuncian los caballeros en numerosas ocasiones en los textos castellanos mediante la fórmula «PPor Dios y por cortesía!». Así la emplean en la Demanda Melián [53], el rey de Castilbriviel [99], el caballero del torneo [153], Erec [166], el rey Pellés [204], Carides [249], Samaliel [309], Bleoberís [430].

${ }_{59}$ Disponemos de pocas menciones a la formación de la escritura en los niños, pero los ejemplos de Merlín, que aprende de su padre el diablo (Jean Colonna [1298-1344?], Mare historiarum, BNF Latín 4915, f. 283), y de Lanzarote, al que la Dama del Lago pone un preceptor desde niño (Le Livre de messire Lancelot du Lac, BNF fr. 111, f. 7), nos informan sobre las edades y sistemas de instrucción privados. 
de la valoración continua de las acciones individuales. El uso escriturario es instrumental y convive con otros sistemas semiológicos como el de la heráldica y, al menos para los textos franceses, otros simbólicos que emplean imágenes, como las de los amores de Lancelot y Ginebra que descubre Artur, los animales, los colores, etc. Es tónica general que los eventos de escritura y lectura se sucedan e intercalen con los mensajes orales, no siendo siempre advertible la esperable variación diamésica; las cartas trasladadas parcial o completamente en las obras obedecen a una retórica en ocasiones cercana al ars predicandi, pero que parecen mostrar un intenso influjo del discurso oral sublime y un recurso continuo al patetismo. Los mandatos y el uso memorialístico de la escritura, sin embargo, funcionan al dictado de reyes y caballeros que ordenan consignar por escrito instrucciones y los episodios, acciones y muertes que deben ser recordados en el libro de la «historia». La capacidad de anticipar el futuro desde algunas instancias y personajes permitiría aventurar además incluso un genus profético, ajeno a la oralidad y que exigiría un desciframiento especializado de su sentido encriptado. Por otra parte, emerge con claridad una clase de profesionales -clérigos y hombres buenos- dedicados a la ordenación y acumulación de la memoria del reino. Los soportes se encuentran aparentemente especializados: papel para las misivas, pergamino para el dictado de libros que deben permanecer -al menos en los textos más antiguos en francés o en el Baladro-, madera, piedra y mármol para los mensajes e indicaciones epigráficos. La capacidad de los canteros para labrar letras en la piedra amplía el ámbito de quienes adquieren competencias escriturarias en una sociedad libresca que deja poco espacio para el retrato de los estamentos más bajos.

Además de la tematización de los eventos de escritura y lectura, así como su uso auxiliar en el intercambio de mensajes orales -similares a los de otros textos como el Libro de Apolonio-, los escritos artúricos componen un vasto sistema de significación estructurado en varios niveles. El primero consiste en un conjunto de referencias intratextuales que sirven de orientación a los caballeros a través de su destino y de la misma trama: padrones de valor profético, indicaciones inscritas, papeles justificativos, epitafios que preservan la memoria de los héroes y sus aventuras como ejemplo moralizador o desencadenante de acciones. En un nivel diferente se encuentra la escritura como manifestación de Dios en la esfera terrena y como orientación de la Providencia, que suele articularse en paralelo a alguna forma de milagro. En un tercer plano, la escritura en latín ordenada por el rey a los clérigos a partir de la recogida de testimonios orales en vulgar, o la dictada por Merlín a Blaise, en la que se narra el conjunto de las aventuras, donde la escritura es un sistema de aseguramiento de la memoria y de su finalidad ética y didáctica. Finalmente, la conversión de los hechos conservados en discurso mediante la reescritura consciente y la emergencia del redactor en lengua romance (Walter Map, 
Robert de Boron) o traductor (Juan Vivas y otros anónimos) ante los ojos u oídos del lector. La finalidad del proceso de metaescritura consiste en organizar el sentido del relato, interviniendo a partir de los propios mecanismos de articulación novelesca. La escritura en prosa es la base de la compleja arquitectura, mientras que, en cualquier caso, se sigue dirigiendo a un auditorio mediante técnicas propias de la oralidad. La potencia de organización textual que ofrece el artificio de la metaficción en prosa, la facilidad para articular diferentes niveles narrativos y para adaptarse a sucesivos horizontes de lectura, redunda en la sensación de espesor de veracidad y facilita los procesos de ciclificación de los textos y contenidos autónomos. Pasados los siglos y afianzada la escritura frente a la voz, debió de sentirse primero como una forma manierismo y, finalmente en los ámbitos italiano e hispánico, como un artificio parodiable, aunque aún pleno de utilidad y fascinación literarias.

\section{APÉNDICE ICONOGRÁFICO}

Son numerosas las iluminaciones de los siglos XIII-XV que incluyen referencias a la lectura de cartas y libros, especialmente las escenas de santos y bíblicas. Aunque en el caso de la literatura artúrica el número de escenas de lectura se restringen a una serie codificada, muchas son trabajos tardíos de maestros iluminadores y no contamos con imágenes de talleres hispánicos que incluyan el tema, los testimonios trasladan con veracidad el ambiente y la materialidad de las prácticas escriturarias: cartas en papel, cálamos, dictados y lectura en público, sagradas escrituras e inscripciones epigráficas. Como es característico en todos los idiomas, las cartas y escenas de lectura con mensajeros abundan en los tristanes, en tanto que Merlín aparece asociado especialmente al acto de dictar y escribir y en las escenas de la Mesa Redonda y el fin de los caballeros en la búsqueda hacen frecuente la aparición de las inscripciones talladas. Los programas iconográficos repiten escenas estereotipadas de gran intensidad narrativa -los procesos de cartas entre Iseo y Tristán, como la jura ante la Biblia, la escritura de los sucesos y profecías, etc.pero también una multitud de episodios menores donde se da cuenta de numerosos detalles relacionados con la cultura escrita, en la que esta desempeña el papel de motor narrativo o desencadena la anagnórisis de un personaje o trama, que aparece al mismo tiempo a los ojos de los protagonistas y de los lectores. Su visionado de forma conjunta con la lectura de los textos facilita la contextualización de los pasajes y motivos, su identificación tipológica, a la vez que revela la cotidianidad de la escritura y la lectura en el ámbito aristocrático alcanzada a partir del siglo XII en el ámbito franco-borgoñón, pronto exportado a otros ámbitos culturales europeos. 


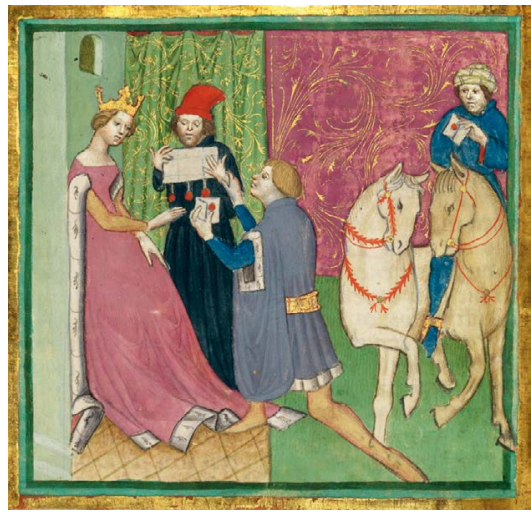

Figura 1

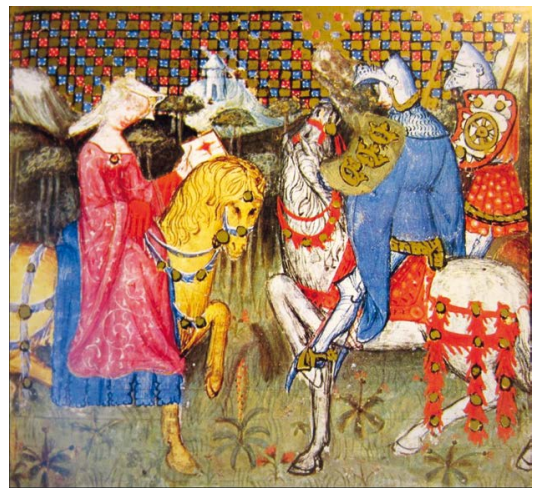

Figura 3

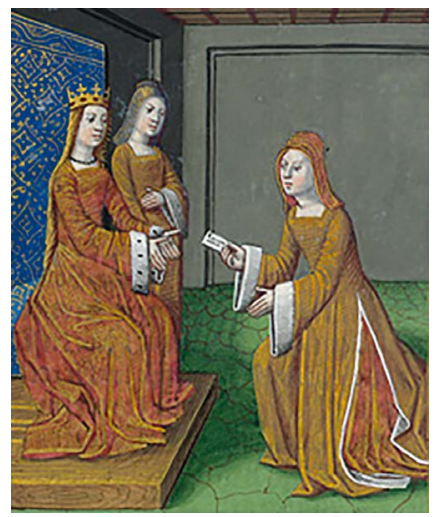

Figura 2

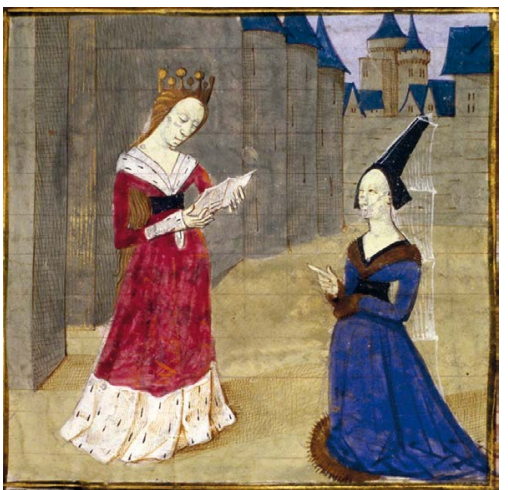

Figura 4

Fig. 1. Wolfram von Eschenbach, Titurel, c. 1270. Ms. Fernberger-Dietrichstein Bayerische Staatsbibliothek. La escena ofrece las secuencias de la llegada de un mensajero, la entrega de una carta lacrada a la reina, así como su lectura en voz alta.

Fig. 2. «Comment la royne Yseult de Cornouaille se complaint a la royne Gemeux de ses amours». Tristan de Léonois, París, Antoine Vérard. BnF, Réserve des livres rares, Vélins 623, f. 70r. Entrega de la carta de Iseo con sus quejas de amor.

Fig. 3. Rommant de Tristan et de Yseult, c. 1410. Österreichische Nationalbibliothek, cod. 2537, f. 98r. Mensajera entregando una carta al rey Artur en medio del camino. El ms., que fue propiedad de Jean de Berry, muestra una gran atención a la heráldica.

Fig. 4. «Iseut leyendo la carta y la mensajera de Guenièvre». Tristan de Léonois, c. 1470 . BNF, fr 102 f. 77. 


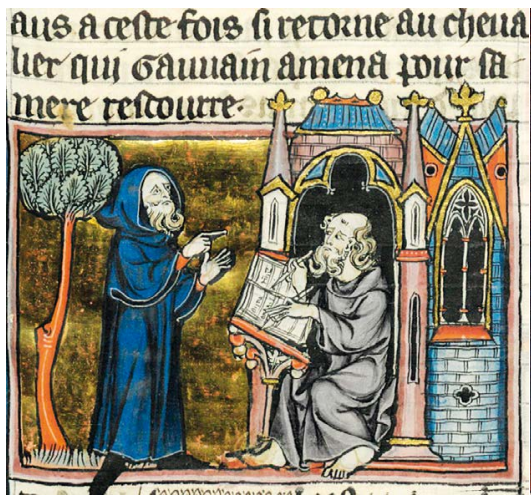

Figura 5

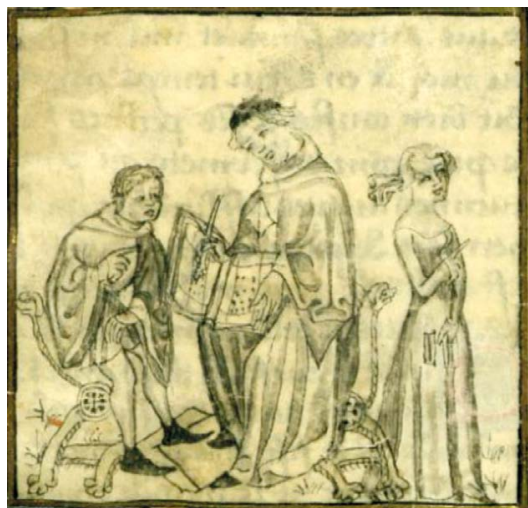

Figura 7

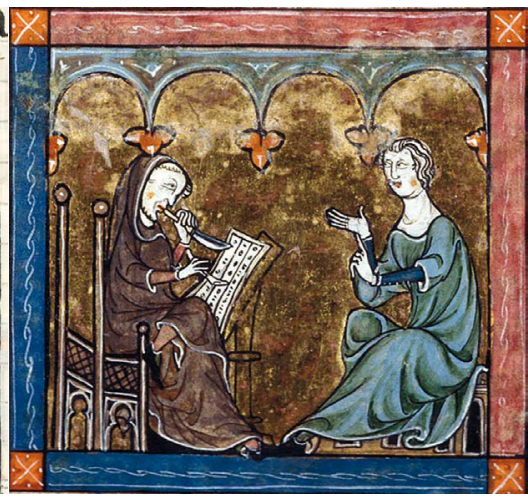

Figura 6

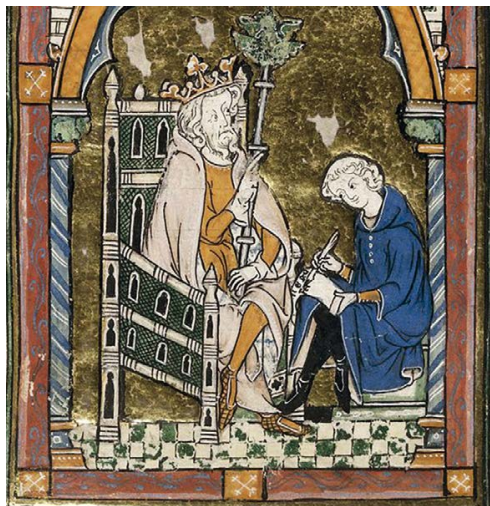

Figura 8

Fig. 5. «Merlín dictando a Blaise». Robert de Boron, L'Estoire del Saint Graal, c. 12701290, BNF fr 95, f. 223r.

Fig. 6. «Blaise escribe las aventuras de Gawain», L'Estoire de Merlin, c. 1316, BL Add. 10292, f. 137r.

Fig. 7. «Merlin profetiza el nacimiento de Belic de Belistans», Les Prophéties de Merlin, s. xv Bibliothèque de l'Arsenal ms 5229 réserve, f. 1r.

Fig. 8. «El rey Arturo dicta a un escriba las aventuras», Mort Artu, c. 1300. BL Royal 14 E III, f. 140r. 


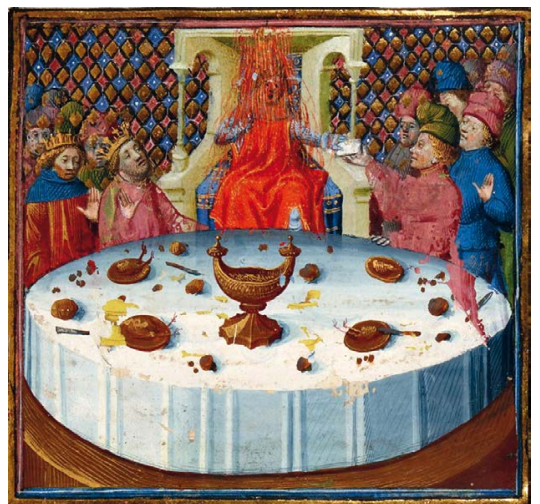

Figura 9

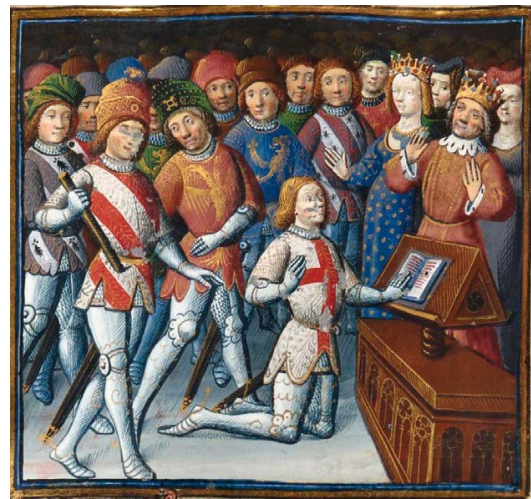

Figura 11

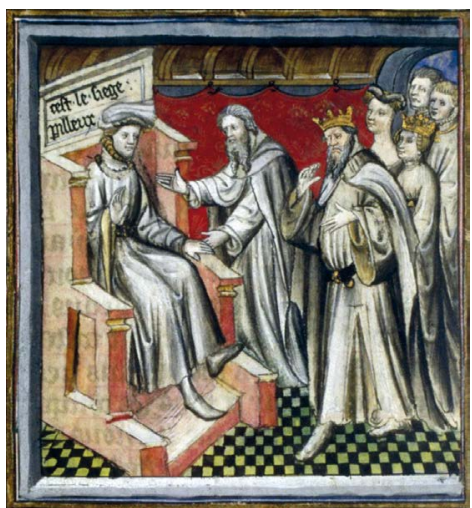

Figura 10

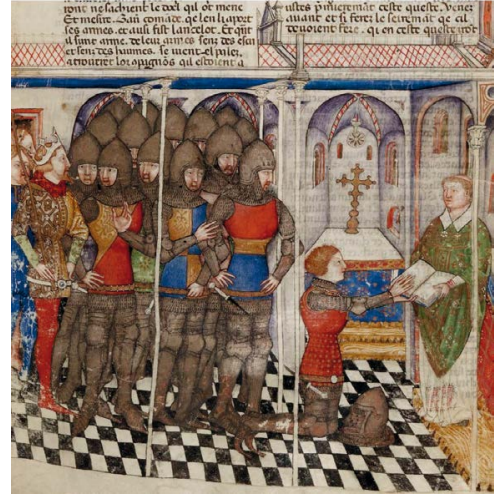

Figura 12

Fig. 9. «Muerte en la Silla peligrosa de Brumant el Orgulloso, sobrino de Claudás». En el momento de arder, entrega a Lancelot una carta donde aclara su identidad y explica sus motivaciones. Lancelot-Graal. BNF fr. 120, 474r.

Fig. 10. «Galaad se sienta en la Silla Peligrosa». Sobre la cátedra aparece la inscripción maravillosa del propietario. Tristan de Léonois, BNF fr. 101, f. 204r.

Fig. 11. «Galaad jura ante las Sagradas Escrituras». Lancelot-Graal iluminado por el maestre des cleres femmes. BNF fr. 120, f. 526r. Enlace: <https:/gallica.bnf.fr/ ark:/12148/btvlb84920806>.

Fig. 12. «Juramento de Galaad». Gautier Map, La Quête du Saint Graal y la Mort d'Arthus, 1380-1385. BNF, fr. 34, f. 7r. 


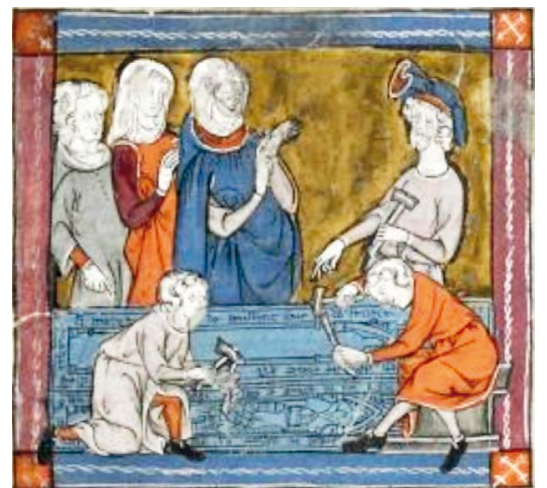

Figura 13

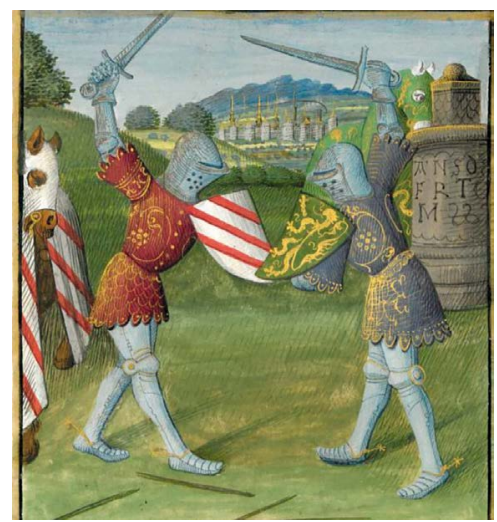

Figura 15

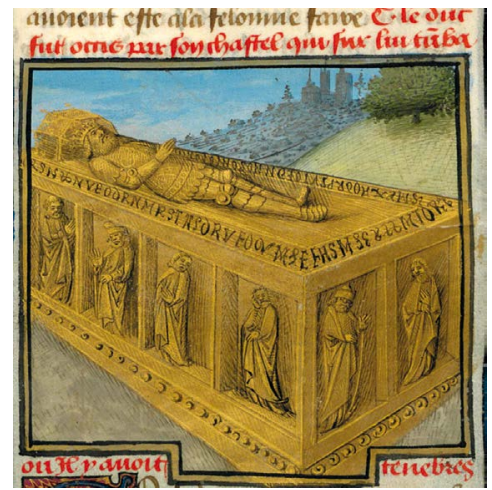

Figura 14

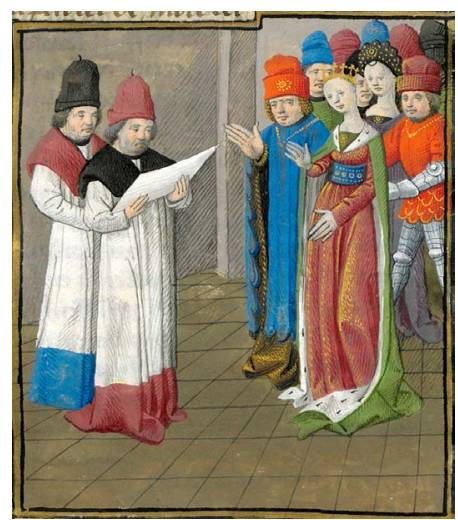

Figura 16

Fig. 13. «Ensi que une duchise fet taillier les tombes et les lettres escrire» de Nabor y Sire Karabel entretalladas con la fecha «le dousieme iour de feveir lan de grace MCCC et XVI», que permite fechar el manuscrito en 1316. L'estoire del Saint Graal, c. 1316. BL Additional 10292 , f. $55 \mathrm{v}$

Fig. 14. «Comment le duc fut occis par son chastel qui sur lui tumba où il y avoit tenebres». Sepulcro con estatua yacente de Lanzarote el Viejo, decapitado por el duque de Bellegarde junto a la Fuente hirviente. Histoire du Saint Graal, iluminada por Evrard d' Espinque, c. 1470. BNF fr. 113, f. 116r.

Fig. 15. Combate entre Lancelot y Tristán junto al padrón con inscripciones epigráficas. Mort le roi Artu, iluminado por Evrard d' Espinque, c. 1480. BNF fr. 116, f. 674 r.

Fig. 16. Ginebra engañada por Mordred mediante cartas falsificadas, que leen en la corte los obispos. Mort le roi Artu, c. 1480. BNF fr. 116 f. $713 \mathrm{v}$.

Enviado: 21/10/2019

Aceptado: 6/03/2020 


\title{
$\cos$
}

\author{
ESCRITURA, MEMORIA Y NARRATIVA \\ EN LA LITERATURA ARTÚRICA HISPÁNICA
}

RESUMEN: La escritura en la Edad Media constituye un sistema de salvaguarda de los hechos dignos de recuerdo y su dominio, además de permitir la construcción de la versión de la historia, es un indicador de poder sobre la realidad y de prestigio social. En la literatura artúrica en prosa, la mención de la escritura en los textos, más allá de su papel intrínseco como vehículo de cultura y de memoria, sirve de mecanismo para otorgar verosimilitud a algunas maravillas o informar de ellas a los caballeros. El artículo estudia las principales alusiones a la escritura y la lectura como reflejo de la cultura caballeresca y cortés, así como su uso en el plano de la metaficción, en el que se emplean para ordenar los acontecimientos, suprimir o modificar episodios, y reflexionar sobre la propia escritura y su valor ante el lector/oidor.

Palabras ClaVe: Memoria, Escritura, Metaficción, Literatura artúrica, Motivos caballerescos.

\section{Writing, MEMORY, AND NARRATIVE in HisPanic Arthurian Literature}

\begin{abstract}
Writing in the Middle Ages constitutes a system of safeguarding the facts worthy of remembrance and its control, in addition to allowing the construction of history, is an indicator of power and social prestige. In the arthurian literature in prose, the mention of writing in texts, beyond its intrinsic role as a vehicle of culture and memory, serves as mechanism to confer verisimilitude to some marvels or to inform the knights of them. The article studies the main allusions to writing and reading as a reflection of chivalrous and courteous culture, and its use in the metafiction plane, in which they are used to order the events, suppress or modify episodes, and reflect on writing itself and its value to the reader / listener.
\end{abstract}

Keywords: Memory, Writing, Metafiction, Arthurian literature, Motifs of Chivalry. 